\title{
Plasticity in Brainstem Mechanisms of Pain Modulation by Nicotinic Acetylcholine Receptors in the Rat
}

\author{
(1)Francis J. Jareczek, ${ }^{1,2}$ Stephanie R. White, ${ }^{3}$ and ${ }^{\circledR D o n n a}$ L. Hammond ${ }^{2,3,4}$
}

DOI:http://dx.doi.org/10.1523/ENEURO.0364-16.2017

${ }^{1}$ Medical Scientist Training Program, University of lowa, lowa City, IA 52242, ${ }^{2}$ Interdisciplinary Graduate Program in Neuroscience, University of lowa, lowa City, IA 52242, ${ }^{3}$ Department of Anesthesia, University of lowa, lowa City, IA 52242, and ${ }^{4}$ Department of Pharmacology, University of lowa, lowa City, IA 52242

\section{Visual Abstract}

\section{Epibatidine in the RVM}

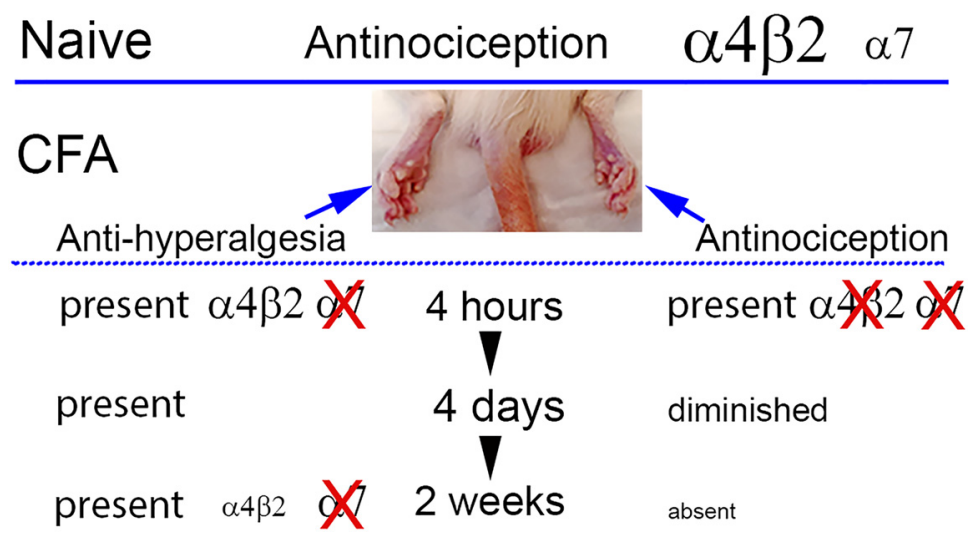

Individuals with chronic pain may be driven to smoke more because the analgesic efficacy of nicotine diminishes. To determine whether persistent pain diminishes the actions of a nicotinic acetylcholine receptor (nAChR) agonist in pain modulatory pathways, we examined the effects of epibatidine in the rostral ventromedial medulla (RVM) of rats with and without inflammatory injury induced by intraplantar injection of complete Freund's adjuvant (CFA). In uninjured rats, epibatidine produced a dose-dependent antinociception that was completely blocked by dihydro- $\beta$-erythroidine (DH $\beta \mathrm{E} ; \alpha 4 \beta 2$ antagonist) and partially blocked by methyllycaconitine (MLA; $\alpha 7$ antagonist). Epibatidine reversed heat hyperalgesia when microinjected in the RVM 4 h, 4 d, or 2 weeks after CFA treatment. Although $\mathrm{DH} \beta \mathrm{E}$ completely blocked epibatidine's antihyperalgesic effect at $4 \mathrm{~h}$, at 2 weeks it elicited only partial antagonism. Methyllycaconitine was ineffective at both time points. Epibatidine's antinociceptive efficacy in the uninjured hind paw progressively declined, and it was without effect 2 weeks after CFA. Moreover, as early as 4 $\mathrm{h}$ after CFA, the antinociceptive effect of epibatidine was no longer antagonized by $\mathrm{DH} \beta \mathrm{E}$. Neither antagonist

\section{Significance Statement}

This article presents evidence that, over time, inflammatory injury diminishes the antinociceptive effects of an nAChR agonist in the brainstem and changes the receptors that mediate the agonist's antihyperalgesic and antinociceptive effects. These data support the clinical hypothesis that those in chronic pain smoke more as a result of a decrease in the analgesic efficacy of $n A C h R$ activation. 
alone altered paw withdrawal latency in uninjured or CFA-treated rats, suggesting that neither $\alpha 4 \beta 2$ nor $\alpha 7$ nAChRs are tonically active in the RVM. The $B_{\max }$ and $K_{d}$ of $\alpha 4 \beta 2$ nAChRs in the RVM were unchanged after CFA treatment. These observations provide the first evidence of pharmacological plasticity of the actions of $\alpha 4 \beta 2$ $\mathrm{nAChR}$ agonists in a critical brainstem pain modulatory pathway and may in part explain why people with chronic pain smoke more than the general population.

Key words: antinociception; complete Freund's adjuvant; epibatidine; nicotinic acetylcholine receptors; rostral ventromedial medulla

\section{Introduction}

Smoking and chronic pain both present significant health care burdens, and the well-established interaction between the two only worsens the overall toll they exert on both individuals and society (Centers for Disease Control and Prevention, 2004, 2010; Ditre et al., 2011; Institute of Medicine, 2011; World Health Organization, 2011). Observational studies find that smoking rates are positively correlated with pain severity and its resulting functional impairment, and analogously, smoking exacerbates both the intensity and associated impairment of chronic pain (Ditre and Brandon, 2008; Hooten et al., 2011; Patterson et al., 2012). Effectively, a positive feedback loop appears to be initiated: individuals smoke to relieve their pain, smoking exacerbates the pain, and individuals smoke more in response.

In nonsmoking humans, nicotine relieves acute pain and decreases opiate analgesic consumption in the acute postoperative setting (Hong et al., 2008; Yagoubian et al., 2011; Ditre et al., 2016). Nicotine has high affinity for $\alpha 4 \beta 2$ nicotinic acetylcholine receptors (nAChRs; Wonnacott and Barik, 2007; Wonnacott, 2014), and nAChR agonists that selectively target $\alpha 4 \beta 2$ nAChRs have shown efficacy in clinical trials but with a narrow therapeutic index (Decker et al., 2001; Jones and Dunlop, 2007; Rowbotham et al., $2009,2012)$. Studies in rodents suggest that the spinal cord, periaqueductal gray (PAG), and rostral ventromedial medulla (RVM) are important sites of action of $n A C h R$ agonists (Umana et al., 2013). Of these, the RVM is of particular interest because it is a critical relay nucleus in endogenous pain modulatory pathways. The RVM receives afferents from more rostral nuclei (e.g., PAG, amygdala) implicated in modulating nociception (Heinricher et al., 2009; Ossipov et al., 2010) and in turn

Received December 9, 2016; accepted January 12, 2017; First published January 19, 2017

The authors declare no competing financial interests.

Author contributions: F.J.J. and D.L.H. designed research; F.J.J. and S.R.W. performed research; F.J.J. and D.L.H. analyzed data; F.J.J. and D.L.H. wrote the paper.

This work was supported by the National Institutes of Health National Institute of Drug Abuse [Grants R01 DA006736, F30 DA036964, T32 GM007337]

Acknowledgments: We thank Dr. Marta Hamity for thoughtful discussion and encouragement.

Correspondence should be addressed to Donna L. Hammond, PhD, Department of Anesthesia, 3000 ML, 200 Hawkins Drive, lowa City, IA 52242. E-mail: donna-hammond@uiowa.edu.

DOI:http://dx.doi.org/10.1523/ENEURO.0364-16.2017

Copyright (C) 2017 Jareczek et al.

This is an open-access article distributed under the terms of the Creative Commons Attribution 4.0 International, which permits unrestricted use, distribution and reproduction in any medium provided that the original work is properly attributed. projects directly to the dorsal horn, where it either facilitates or inhibits the transmission of nociceptive information (Ren and Dubner, 1999, 2002; Millan, 2002; Vanegas, 2004; Vanegas and Schaible, 2004). Microinjection of the $\alpha 4 \beta 2$ nAChR agonist ABT-594 in the RVM is sufficient to produce antinociception (Bannon et al., 1998). Activation of $\alpha 4 \beta 2$ nAChRs specifically in the RVM also appears to be necessary for nicotinic antinociception: inactivation with lidocaine or microinjection of $\mathrm{nAChR}$ antagonists in the RVM antagonizes the antinociceptive effects of systemically administered nicotine and epibatidine (Curzon et al., 1998; Decker et al., 1998).

Many hypotheses have been put forward to explain why chronic pain is so poorly managed in smokers. The proposed mechanisms focus largely on biological processes such as inflammation, poor perfusion, ischemia, poor wound healing, nitric oxide production, and nutrition (Ditre et al., 2011). However, little attention has been paid to the role that adaptive changes in the CNS play in this phenomenon. Nociceptive sensitivity reflects the net sum of activity in bulbospinal pain facilitatory and pain inhibitory pathways. Persistent pain states effect substantial changes in the physiology and pharmacology of the bulbospinal pain pathways, altering the balance between facilitation and inhibition (Ren and Dubner, 1999, 2002; Vanegas, 2004; Vanegas and Schaible, 2004). These changes have ramifications for the antinociceptive potency and efficacy of drugs that act in key nuclei, such as enhancement of the antihyperalgesic and antinociceptive effects of $\mu$-opioid receptor agonists in the RVM (Hurley and Hammond, 2001; Schepers et al., 2008).

We hypothesized that persistent pain states may lead to a time-dependent decrease in the antihyperalgesic and antinociceptive efficacy of nAChR agonists in the RVM. This hypothesis was tested by microinjection of epibatidine, a highly potent nAChR agonist, in the RVM of male rats at different times after induction of inflammatory injury by intraplantar injection of complete Freund's adjuvant (CFA). The pharmacological specificity of epibatidine's effects and possible tonic activation of nAChRs was further probed using antagonists of the $\alpha 4 \beta 2$ and $\alpha 7$ nAChR, which represent the two most abundant subtypes of nAChR in the CNS (Wu and Lukas, 2011; Hurst et al., 2013). As the most parsimonious explanation for a change in agonist action would be a loss of receptor number or decrease in affinity, we additionally conducted radioligand binding studies in rats with and without persistent inflammatory injury. The results of these studies partially support our hypotheses but also suggest alternate mechanisms. Taken together, our findings provide the first evidence of adaptive changes in a critical bulbospinal pathway 
through which nAChR agonists act to modulate nociception and support for the postulate that patients with chronic pain may smoke more because their ongoing pain decreases the analgesic effects of nicotine.

\section{Methods and Materials}

\section{Animals}

Adult (8-10 weeks of age) male Sprague-Dawley rats weighing 225-275 g were obtained from Charles River. Female rats were not used because the study was initiated before the National Institutes of Health mandated assessment of sex differences. Moreover, the phenotype of nicotine-induced analgesia is more consistent in men than in women (Shi et al., 2010). All experiments were approved by the University of lowa Animal Care and Use Committee (protocol \#4051048) and were conducted based on guidelines set forth by the National Institutes of Health and the International Association for the Study of Pain. After arrival, the animals were acclimated to the facility for at least $48 \mathrm{~h}$ before use. Animals were housed two per cage on eighth-inch corn cob bedding (cat. no. 7092; Envigo) in a temperature- and humidity-controlled room on a 12-h light/dark cycle with free access to food and water. After intracerebral cannula placement or intraplantar injection of CFA or saline, the rats were housed individually on the same bedding. Every effort was made to minimize the number of animals used and their suffering.

\section{Experimental design for behavioral studies}

The first set of experiments was designed to assess the efficacy and pharmacological specificity of the highly potent $\mathrm{nAChR}$ agonist epibatidine microinjected in the RVM of naive rats and rats after different durations of inflammatory injury. Although the investigator could not be blinded to intraplantar treatment, the person testing the rats was blinded to the test drugs, which were made up by another person and assigned a letter that changed throughout the study. The experimental unit was the rat. Although sample size and power were not specifically determined before the study started, the numbers of rats are consistent with previous work from this laboratory.

\section{Model of hind paw inflammatory injury}

A single injection of $150 \mu \mathrm{l} \mathrm{CFA} \mathrm{(150} \mu \mathrm{g}$ Mycobacterium butyricum, $85 \%$ Drakeol 5NF, and 15\% Aralacel A mannide monooleate emulsifier; cat. no. 344289; Calbiochem) was made into the plantar surface of the left hind paw of rats lightly anesthetized with isoflurane. Intraplantar injection of CFA induces a robust and reproducible inflammatory injury that begins within $1 \mathrm{~h}$ and persists for at least 2 weeks as assessed by paw edema and tests for heat and mechanical hyperalgesia (Nagakura et al., 2003; Hamity et al., 2010). The same volume of physiological saline $(0.9 \%, \mathrm{pH} 7.4)$ was injected in a separate group of animals as a control.

In the CFA model, the withdrawal threshold of the ipsilateral hind paw is greatly diminished, whereas that of the contralateral hind paw is unaffected. Therefore, one can assess the ability of agents to return the threshold of the ipsilateral hind paw to normal values (termed antihyperalgesia) as well as the ability of an agent to further increase the threshold of the contralateral hind paw beyond normal values (termed antinociception). As antihyperalgesia and antinociception are distinct phenomena, comparison of drug effects between ipsilateral and contralateral hind paws is inappropriate. The impact of chronic pain on the antinociceptive effects of drugs (i.e., ability to suppress acute physiological pain) can be assessed by comparison of effects on the contralateral hind paw of CFA-treated rats and naive rats, as well as to the contralateral hind paw of rats with different durations of persistent pain as in this study.

\section{Assessment of nociceptive threshold and paw thickness}

Rats were acclimated to the testing environment for 30 min and then placed in individual Plexiglas chambers situated on a glass surface that was maintained at $25^{\circ} \mathrm{C}$ for another 30-min period of acclimation. Nociceptive sensitivity was measured using the paw withdrawal test, in which a high-intensity beam of light was focused on the plantar surface of the hind paw. The time required for the rat to lift its hind paw from the heat stimulus was termed the paw withdrawal latency (PWL). The high-intensity lamp was adjusted to elicit baseline paw withdrawal latencies of 8-12 s. If a withdrawal response did not occur within $20 \mathrm{~s}$, the test was terminated to prevent tissue injury, and the rat was assigned this latency. Response latencies were determined for the left (injured) and right (uninjured) hind paws. Hind paw thickness in the dorsoventral axis was measured with digital calipers (Ted Pella) before and after intraplantar injection of saline or CFA. All testing was conducted in a small room designated for this work and was completed between the hours of 08:00 and 14:00.

\section{Microinjection studies}

Rats were anesthetized with a mixture of ketamine (70 $\mathrm{mg} / \mathrm{kg}$ i.p.), xylazine (10 $\mathrm{mg} / \mathrm{kg}$ i.p.), and acepromazine (1 $\mathrm{mg} / \mathrm{kg}$ i.p.) and implanted with an intracerebral guide cannula positioned above the RVM (26-gauge; Plastics One). Cannulae were affixed to the skull with stainless steel screws and dental acrylic, and a stainless steel stylet was inserted in the guide cannula to maintain patency. Cannulae were implanted 6 to $9 \mathrm{~d}$ before behavioral testing. The health status of the rats was monitored daily.

All agents were microinjected in a volume of $0.25 \mu \mathrm{l}$ via a 33-gauge stainless steel injector needle that extended 3 $\mathrm{mm}$ beyond the guide cannula tip. Drug was microinjected over $\sim 10 \mathrm{~s}$, and delivery was monitored by following the movement of an air bubble in the tubing that connected the injector to the syringe pump. The needle was left in place for $60 \mathrm{~s}$ after the injection to minimize diffusion of drug up the injection tract. Each rat was used once. Epibatidine (cat. no. E1145; Sigma-Aldrich), dihydro- $\beta$-erythroidine ( $\mathrm{DH} \beta \mathrm{E}$; cat. no. 2349; Tocris), and methyllycaconitine (MLA; cat. no. M168; Sigma-Aldrich) were dissolved in saline. Saline at $\mathrm{pH} 7.4$ was used as the control for all drugs. Doses of the antagonists were based on prior literature (Panagis et al., 2000; Laviolette and van 
der Kooy, 2003; Champtiaux et al., 2006; Tsutsui-Kimura et al., 2010). After behavioral testing, animals were killed by $\mathrm{CO}_{2}$ inhalation. Brains were removed, fixed in $10 \%$ formalin containing $30 \%$ sucrose, and transverse sections cut on a cryostat microtome and stained with Cresyl Violet. Injection sites were identified by two individuals blinded to the behavioral outcome. Microinjection sites that were located in the nucleus reticularis gigantocellularis pars alpha were included with those in the nucleus raphe magnus and collectively referred to as the RVM. Rats were excluded if there was substantial tissue damage at the microinjection site.

\section{Experimental design for radioligand binding studies}

Radioligand binding was used to determine and compare the $B_{\max }$ and $K_{d}$ of $\alpha 4 \beta 2 \mathrm{nAChRs}$ in the RVM $4 \mathrm{~h}, 4$ $\mathrm{d}$, and 2 weeks after intraplantar injection of saline or CFA. An experiment consisted of a cohort of saline- and CFAtreated rats at each of the three time points. Tissue from three rats was pooled to generate a sample, which served as the experimental unit. Three to five independent experiments (biological replicates) were conducted. Although sample size and power were not determined before the study started, the number of replicates is in line with previous work from this laboratory. The individual conducting the binding was blinded to the treatment condition of the homogenates. Rats used for radioligand binding were not subjected to thermal stimuli, as this nociceptive testing has been demonstrated to release endogenous substance P in the RVM (Hamity et al., 2014). In the case of acetylcholine, such release could interfere with determination of $B_{\max }$ and $K_{d}$. However, paw thickness was measured to confirm the presence of inflammation induced by CFA.

\section{Tissue collection for radioligand binding}

Four hours, $4 \mathrm{~d}$, or 2 weeks after intraplantar saline or CFA injection, paw thicknesses were reassessed. The animals were then killed with $\mathrm{CO}_{2}$, exsanguinated, and decapitated. The brainstem was rapidly dissected out, and two transverse cuts were made 3 and $5 \mathrm{~mm}$ rostral to the obex. The resulting 2-mm-thick section was placed on a chilled surface and a triangular region defined at the vertex by the fourth ventricle and at each corner of the lateral edge of the pyramids was dissected free. The pyramids were then removed. The resulting region contained the nucleus raphe magnus and the adjacent bilateral nucleus reticularis gigantocellularis pars alpha. The freshly dissected tissue was collected into Eppendorf tubes on ice and stored at $-80^{\circ} \mathrm{C}$ for no more than $2 \mathrm{~d}$ before being used to prepare membrane homogenates for radioligand binding.

\section{Membrane homogenate preparation}

RVM triangles from three rats in each experimental group were combined, weighed, and thoroughly homogenized in 20 volumes of ice-cold assay buffer $(50 \mathrm{~mm}$ TRIZMA, pH 7.4; Sigma-Aldrich). The homogenate was then centrifuged at $39,000 \times g$ at $4^{\circ} \mathrm{C}$ for $15 \mathrm{~min}$. The supernatant was discarded, 20 volumes of ice cold assay buffer were added, and the pellet was homogenized. The homogenate was incubated at $25^{\circ} \mathrm{C}$ for 10 min before a second centrifugation step at $39,000 \times g$ at $4^{\circ} \mathrm{C}$ for 15 $\mathrm{min}$. The supernatant was again discarded, and the pellet was resuspended in assay buffer. Protein concentration was determined using the Lowry assay. The membrane preparation was stored at $-80^{\circ} \mathrm{C}$ until used for radioligand binding. Membrane preparations were coded to blind the investigator to treatment condition.

\section{Radioligand binding in membrane homogenates}

Dilutions of stock $\left[{ }^{3} \mathrm{H}\right]$ epibatidine $(62.2 \mathrm{Ci} / \mathrm{mmol}$, lot \#1730657 or $54.1 \mathrm{Ci} / \mathrm{mmol}$, lot \#1778835 or \#1828391; cat. no. NET1102; Perkin Elmer) were prepared in assay buffer (50 mM TRIZMA, pH 7.4). All reactions were performed in triplicate with $50 \mu \mathrm{g}$ membrane protein. Binding reactions were terminated by rapid filtration using a Brandel cell harvester and filter paper (Brandel \#FP-100 GF/B) that had been soaked in $50 \mathrm{~mm}$ TRIZMA, pH 7.2, with $0.5 \%$ polyethyleneimine $(\mathrm{w} / \mathrm{v})$ at $4^{\circ} \mathrm{C}$ for at least $2 \mathrm{~h}$ to minimize nonspecific binding.

\section{Kinetic assay: association}

Test tubes were prepared with $50 \mu \mathrm{g}$ of membrane protein and final concentrations of $0.002,0.02$, or $0.2 \mathrm{~nm}$ $\left[{ }^{3} \mathrm{H}\right]$ epibatidine. The membranes and radioligand incubated at $25^{\circ} \mathrm{C}$ in a shaking water bath for $0.5-5 \mathrm{~h}$. Nonspecific binding was determined in the presence of $300 \mu \mathrm{M}$ nicotine (cat. no. N5260; Sigma-Aldrich). Filter discs were washed three times with $5 \mathrm{ml}$ of ice-cold wash buffer $(50 \mathrm{mM}$ TRIZMA, pH 7.2), and then placed in scintillation vials to which $500 \mu \mathrm{l}$ of absolute ethanol was added. Five milliliters of scintillation fluid (Econo-Safe; RPI Corporation) was added $15 \mathrm{~min}$ later, and the vials were shaken for $15 \mathrm{~min}$. Samples were left undisturbed for at least $15 \mathrm{~h}$, then were agitated once more and counted using a Beckman Coulter LS6500 scintillation counter at $40 \%$ efficiency.

\section{Kinetic assay: dissociation}

Test tubes were prepared as described above with a concentration of $0.02 \mathrm{~nm}\left[{ }^{3} \mathrm{H}\right]$ epibatidine. Samples were incubated at $25^{\circ} \mathrm{C}$ in a shaking water bath for $3 \mathrm{~h}$ to allow the binding reaction to reach equilibrium. Dissociation of $\left[{ }^{3} \mathrm{H}\right]$ epibatidine was then initiated by addition of $300 \mu \mathrm{M}$ nicotine. The samples were then incubated for an additional $1-11 \mathrm{~h}$. Nonspecific binding was determined at the 3- and 11-h time points in the presence of $300 \mu \mathrm{m}$ nicotine for the duration of the experiment. The reaction was terminated, and samples were prepared for scintillation analysis as described above.

\section{Saturation assay}

Test tubes were prepared as described above with final $\left[{ }^{3} \mathrm{H}\right]$ epibatidine concentrations ranging from of 0.001 to $2.5 \mathrm{~nm}$. Samples were incubated at $25^{\circ} \mathrm{C}$ in a shaking water bath for $3 \mathrm{~h}$ to allow the binding reaction to reach equilibrium. Nonspecific binding was determined in the presence of $300 \mu \mathrm{M}$ nicotine. The reaction was terminated, and samples were prepared for scintillation analysis as described above. Aliquots of the different $\left[{ }^{3} \mathrm{H}\right]$ epibatidine dilutions were prepared for scintillation analysis to generate concentration-versus-CPM curves. 


\section{Statistical analysis}

Microinjection studies

Data were expressed as the mean \pm SEM. Two-way repeated-measures ANOVA, in which the repeated factor was time and the other factor was treatment, was used to compare PWL among the different groups. Significant overall effects of treatment or time, or a significant interaction of treatment and time, were followed by the HolmSidak test for post hoc comparisons among mean values for the individual treatment groups. Only $p$ values are reported for post hoc tests. Welch's corrected $t$-test was used to compare paw thickness at each time point because it does not assume both groups have equal variance. Statistical analyses were conducted with SigmaPlot 13.0, which also indicated that assumptions of normality (Shapiro-Wilk test) and equal variance (Brown-Forsyth test) were met. A $p<0.05$ was considered significant for this and all subsequent tests.

\section{Radioligand binding studies}

Saturation binding curves of specific binding were fitted by nonlinear regression using GraphPad Prism, and an $F$-test was conducted to determine whether the curves were best fit by a one- or two-site model. If the data were better fitted by a two-site model, the $B_{\max }$ and $K_{d}$ for the high-affinity site were used for analysis. The $B_{\max }$ and $K_{d}$ values were determined for each of three to five independent experiments and were averaged to generate the mean and SEM. Two-way ANOVA in which treatment was one factor and time was the other factor was used to compare $B_{\max }$ and $K_{d}$ values in saline- and CFA-treated rats at each time point. Superscript letters listed with $p$-values correspond to the statistical tests shown in Table 1.

\section{Results}

\section{Actions of epibatidine in the RVM of naive rats}

Microinjection of epibatidine throughout the rostralcaudal extent of the RVM of naive rats produced a doseand time-dependent increase in PWL (treatment $F_{(4,34)}=$ $6.208, p<0.001$; time $F_{(4,136)}=22.363, p<0.001$; interaction $\left.F_{(16,136)}=2.040, p=0.015\right)^{\mathrm{a}}$ (Fig. $1 A$ and inset). The increase was short-lived, with peak effect observed within 10 min of injection $(p<0.001)$. Fig. 2 depicts the distribution of microinjection sites in the RVM for the 4.11-ng treatment group, which is representative of the distribution of RVM sites in all other treatment groups. In general, microinjection of the highest dose of epibatidine at sites dorsal to or outside the RVM did not increase PWL compared with baseline values $(10.9 \pm 0.8 \mathrm{~s}$ at $10 \mathrm{~min} ; n=8$; one-way ANOVA $F_{(7,28)}=0.818, p=$ $0.525)^{\mathrm{b}}$, although sites that impinged on the lateral or rostral borders of the RVM could yield modest increases in PWL.

The antinociceptive effect of epibatidine was challenged by pretreatment with $5 \mu \mathrm{g} \mathrm{DH} \beta \mathrm{E}$, a competitive $\alpha 4 \beta 2$ nAChR antagonist (Daly, 2005; Wonnacott and Barik, 2007; Wonnacott, 2014) or $1 \mu \mathrm{g}$ MLA, a competitive $\alpha 7$ nAChR antagonist (Daly, 2005; Wonnacott and Barik, 2007; Wonnacott, 2014). These two antagonists differentially attenuated the effects of epibatidine (treatment $F_{(2,16)}$
$=3.696, p=0.048$; time $F_{(4,62)}=11.328, p<0.001$; interaction $\left.F_{(8,62)}=2.439, p=0.023\right)^{c}$. Pretreatment with $\mathrm{DH} \beta \mathrm{E}$ completely blocked the antinociceptive effect of the highest dose of epibatidine $(p<0.001)$, whereas challenge with MLA partially attenuated the antinociceptive effects of epibatidine $(p=0.003$; Fig. $1 B)$. One rat in the latter group adopted a cataleptic stance $45 \mathrm{~min}$ after injection, which interfered with PWL measurements at 45 and $60 \mathrm{~min}$. A higher dose of MLA, $3 \mu \mathrm{g}$, by itself significantly increased PWL (data not shown), which precluded challenge of epibatidine with a higher dose of MLA. These data suggest an additional involvement of $\alpha 7 \mathrm{nAChRs}$ in the effects of the highest dose of epibatidine.

To assess whether tonic activation of nAChRs was present, $5 \mu \mathrm{g} \mathrm{DH} \beta \mathrm{E}$ or $1 \mu \mathrm{g}$ MLA was injected $20 \mathrm{~min}$ before microinjection of saline in the RVM. This design mirrored the design used in the pharmacological challenge of epibatidine so that the effect of each antagonist was assessed at the same time point as when its antagonism of epibatidine was determined. Compared with the effect of saline, microinjection of either $5 \mu \mathrm{g} \mathrm{DH} \beta \mathrm{E}$ or $1 \mu \mathrm{g}$ MLA did not alter PWL (treatment $F_{(2,16)}=1.181, p=$ 0.332 ; interaction $\left.F_{(8,64)}=1.824, p=0.089\right)^{\mathrm{d}}$, suggesting that little tonic activation of $\alpha 4 \beta 2$ or $\alpha 7 \mathrm{nAChRs}$ exists in the RVM (Fig. 1C). Within-treatment comparison (time $\left.F_{(4,64)}=10.012, p<0.001\right)$ indicated that microinjection of $5 \mu \mathrm{g} \mathrm{DH} \beta$ E transiently increased paw withdrawal compared with baseline $(p<0.001)$, whereas saline did not $(p$ $=0.923$ ). Nonetheless, the lack of treatment effect does not support tonic activation of $\alpha 4 \beta 2 \mathrm{nAChRs}$ in the RVM.

\section{Impact of peripheral inflammatory injury on the antihyperalgesic and antinociceptive actions of epibatidine in the RVM}

Intraplantar injection of CFA in the hind paw uniformly produced robust and reproducible inflammation as indicated by hind paw edema at $4 \mathrm{~h}, 4 \mathrm{~d}$, and 2 weeks after injection. The thickness of the CFA-injected hind paw was significantly greater than baseline thickness at each time point ( 4 h: $10.3 \pm 0.1$ vs. $6.3 \pm 0.01(n=38) ; 4$ d: $9.9 \pm$ 0.2 vs. $6.0 \pm 0.05$ ( $n=13) ; 2$ weeks: $9.6 \pm 0.2$ vs. $6.2 \pm$ $0.01 \mathrm{~mm}(n=60 ; 4 \mathrm{~h}$ Welch-corrected $t=69.02, \mathrm{df}=$ 40.16; 4 d Welch-corrected $t=17.02$, df $=13.09 ; 2$ weeks Welch-corrected $t=21.22, \mathrm{df}=60.11, \mathrm{p}<0.001$ for all three time points) or the uninflamed, contralateral hind paws (data not shown).

Epibatidine completely reversed heat hyperalgesia within 10 min of its microinjection in the RVM. The effect dissipated over the next $45 \mathrm{~min}$. Of note, epibatidine did not further increase PWL beyond baseline values. The antihyperalgesic effect of epibatidine was unchanged $4 \mathrm{~h}$ (treatment $F_{(1,12)}=28.466, p<0.001$; time $F_{(5,60)}=$ $22.568, p<0.001$; interaction $\left.F_{(5,60)}=6.229, p<0.001\right)^{f}$, $4 \mathrm{~d}$ (treatment $F_{(1,11)}=11.726, p=0.006$; time $F_{(5,54)}=$ $11.108, p<0.001$; interaction $\left.F_{(5,54)}=3.272, p=0.012\right)^{\mathrm{g}}$, and 2 weeks (treatment $F_{(1,15)}=2.431, p=0.140$; time $F_{(5,75)}=13.682, p<0.001$; interaction $F_{(5,75)}=2.507, p=$ $0.037)^{\mathrm{h}}$ after CFA treatment (Fig. $\left.3 A-C\right)$. In contrast, the antinociceptive effect of epibatidine in the contralateral, uninflamed hind paw progressively decreased in a time- 
Table 1. Statistical analysis.

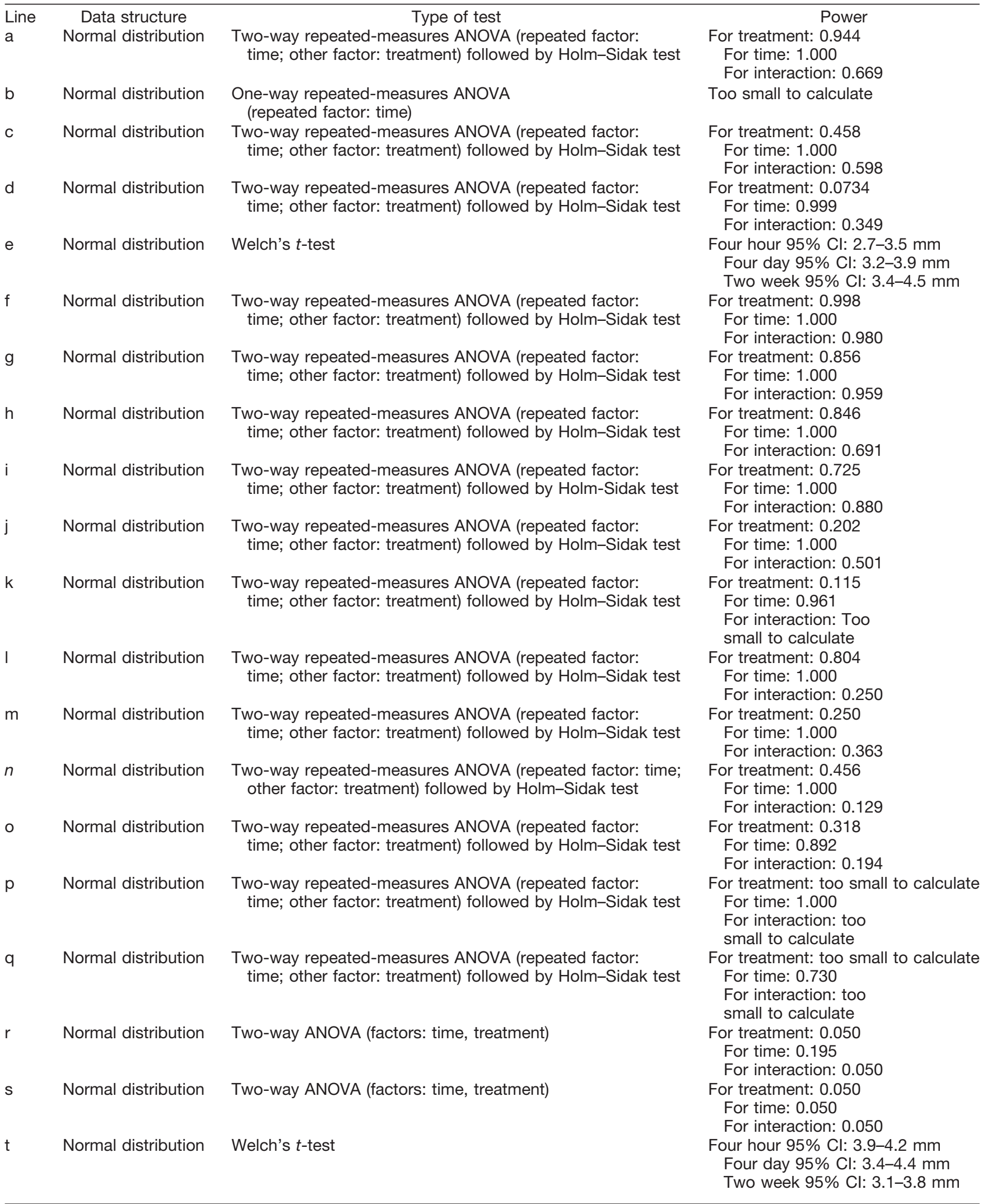

$\mathrm{Cl}$, confidence interval. 


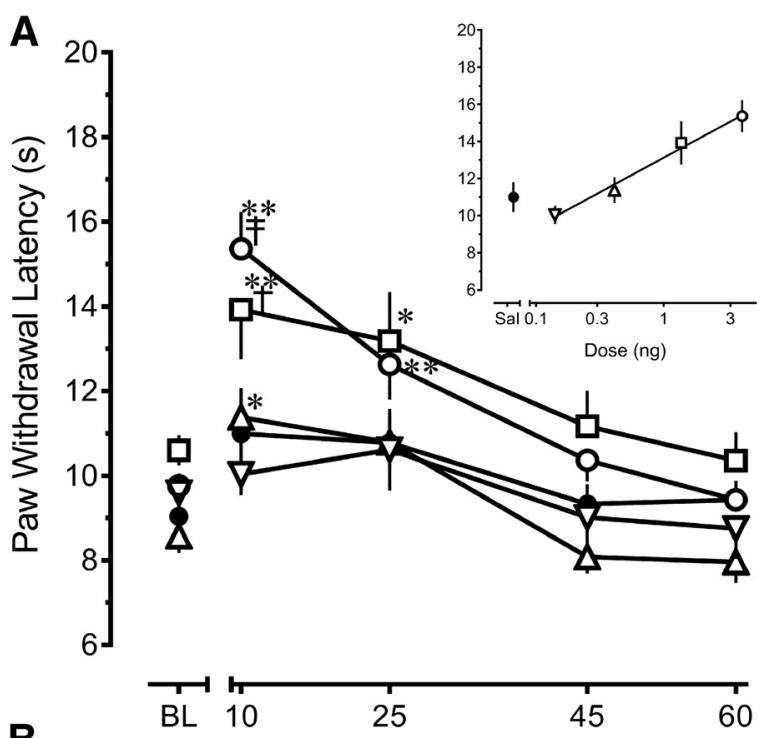

B
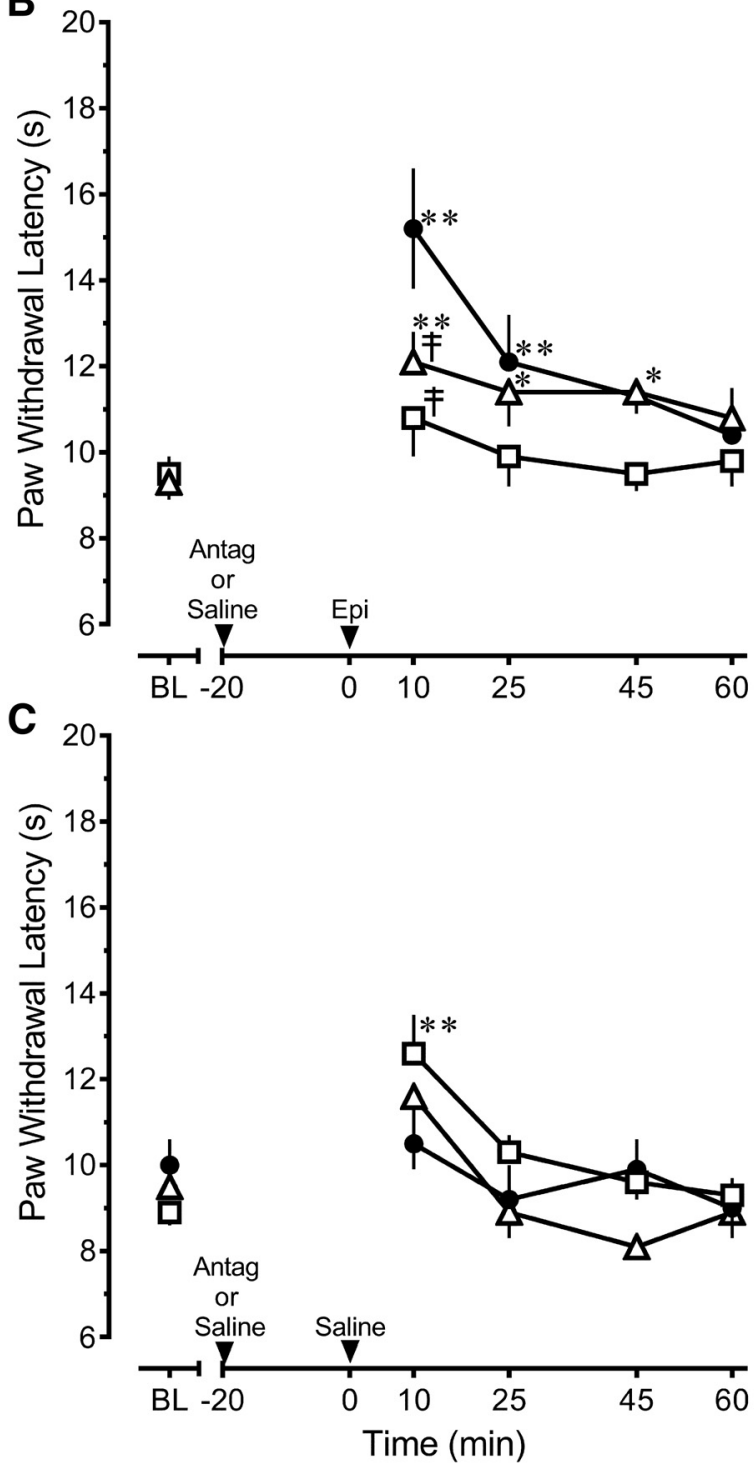

Fig. 1. The antinociception produced by epibatidine in the rostral ventromedial medulla of uninjured rats is principally mediated by
Fig. 1. continued

$\alpha 4 \beta 2$ nAChRs, which do not appear to be tonically active. $\boldsymbol{A}$, Microinjection of epibatidine (Epi) produces a dose-dependent increase in PWL to noxious heat $\bigcirc: 4.11 \mathrm{ng}, n=14 ; \square: 1.37 \mathrm{ng}$, $n=6 ; \Delta: 0.41 \mathrm{ng}, n=5 ; \nabla: 0.14 \mathrm{ng}, n=5 ; 0$ : saline, $n=9 . \mathbf{B}$, Prior microinjection of $5 \mu \mathrm{g}$ of the $\alpha 4 \beta 2 \mathrm{nAChR}$ antagonist $\mathrm{DH} \beta \mathrm{E}$ $\square, n=6)$ completely blocks the effect of the highest dose of epibatidine $(4.11 \mathrm{ng})$ compared to pretreatment with saline $(\mathbf{O}$ $n=6)$, whereas $1 \mu \mathrm{g} \operatorname{MLA}(\Delta, n=7)$ produces a partial antagonism. C, Compared with saline $(\boldsymbol{O}, n=6)$, microinjection of $5 \mu \mathrm{g} \mathrm{DH} \beta \mathrm{E}(\square, n=8)$ or $1 \mu \mathrm{g} \mathrm{MLA}(\Delta, n=5)$ did not alter PWL in rats that subsequently received saline at the same site. Data are mean \pm SEM. Latencies for left and right hind paws were averaged to yield a single value for each rat in all panels. BL, baseline PWL. $* p<0.05, * * p<0.01$ compared with baseline values. ${ }^{\dagger} p<0.05,{ }^{\ddagger} p<0.01$ compared with saline control at the corresponding time point. Two-way repeated-measures ANOVA followed by Holm-Sidak test.

dependent manner in CFA-treated rats (Fig. 3D-F). As in naive rats, microinjection of $4.11 \mathrm{ng}$ epibatidine in the RVM of rats treated $4 \mathrm{~h}$ earlier with CFA significantly increased PWL of the uninjured hind paw for a period of $25 \mathrm{~min}$, with the peak effect at $10 \mathrm{~min}$ (treatment $F_{(1,12)}=$ 11.865, $p=0.005$; time $F_{(5,60)}=15.555, p<0.001$; interaction $\left.F_{(5,60)}=5.526, p<0.001\right)^{i}$ (Fig. 3D). When examined $4 \mathrm{~d}$ after CFA (Fig. $3 E$ ), the magnitude of the increase in PWL was unchanged, but the duration of the effect was truncated (treatment $F_{(1,11)}=8.903, p=0.013$; time $F_{(5,54)}=10.662, p<0.001$; interaction $F_{(5,54)}=$ $4.445, p=0.002)^{j}$. In rats that had received an injection of CFA 2 weeks earlier, microinjection of $4.11 \mathrm{ng}$ epibatidine in the RVM did not increase PWL in the contralateral hind paw compared to the effects of saline (treatment $F_{(1,15)}=$ $1.625, p=0.222$; time $F_{(5,75)}=5.505, p<0.001$; interaction $\left.F_{(5,75)}=0.715, p=0.614\right)^{\mathrm{k}}$.

Given that the antihyperalgesic and antinociceptive effects of epibatidine were differently affected in the presence of persistent inflammatory injury, the pharmacological specificity of epibatidine was reexamined both $4 \mathrm{~h}$ and 2 weeks after CFA treatment. Four hours after CFA, comparison of the effects of $D H \beta E$ or MLA to that of saline for the ipsilateral inflamed hind paw (treatment $F_{(2,22)}=$ 6.596, $p=0.006$; time $F_{(5,110)}=81.184, p<0.001$; interaction $\left.F_{(10,110)}=1.505, p=0.147\right)^{1}$ indicated that challenge with $5 \mu \mathrm{g} \mathrm{DH} \beta \mathrm{E}$ completely blocked the antihyperalgesic effect of epibatidine $(p=0.003$; Fig. $4 A$ ). Challenge with $1 \mu \mathrm{g}$ MLA did not attenuate the antihyperalgesic effects of epibatidine at this time point $(p=0.287$ ). Surprisingly, analysis of the contralateral uninflamed hind paw (treatment $F_{(2,22)}=2.291, p=0.125$; time $F_{(5,110)}=$ $37.910, p<0.001$; interaction $F_{(10,110)}=1.728, p=$ $0.083)^{\mathrm{m}}$ indicated that neither $\mathrm{DH} \beta \mathrm{E}(p=0.101)$ nor MLA $(p=0.151)$ attenuated the antinociceptive effects of epibatidine (Fig. 4B), unlike findings in naive rats (Fig. 1B). These data indicate that the antihyperalgesic effects in the period immediate to injury were predominantly mediated by $\alpha 4 \beta 2 \mathrm{nAChRs}$, but that the antinociceptive effects of epibatidine were no longer mediated by either $\alpha 4 \beta 2$ or $\alpha 7$ nAChRs. 

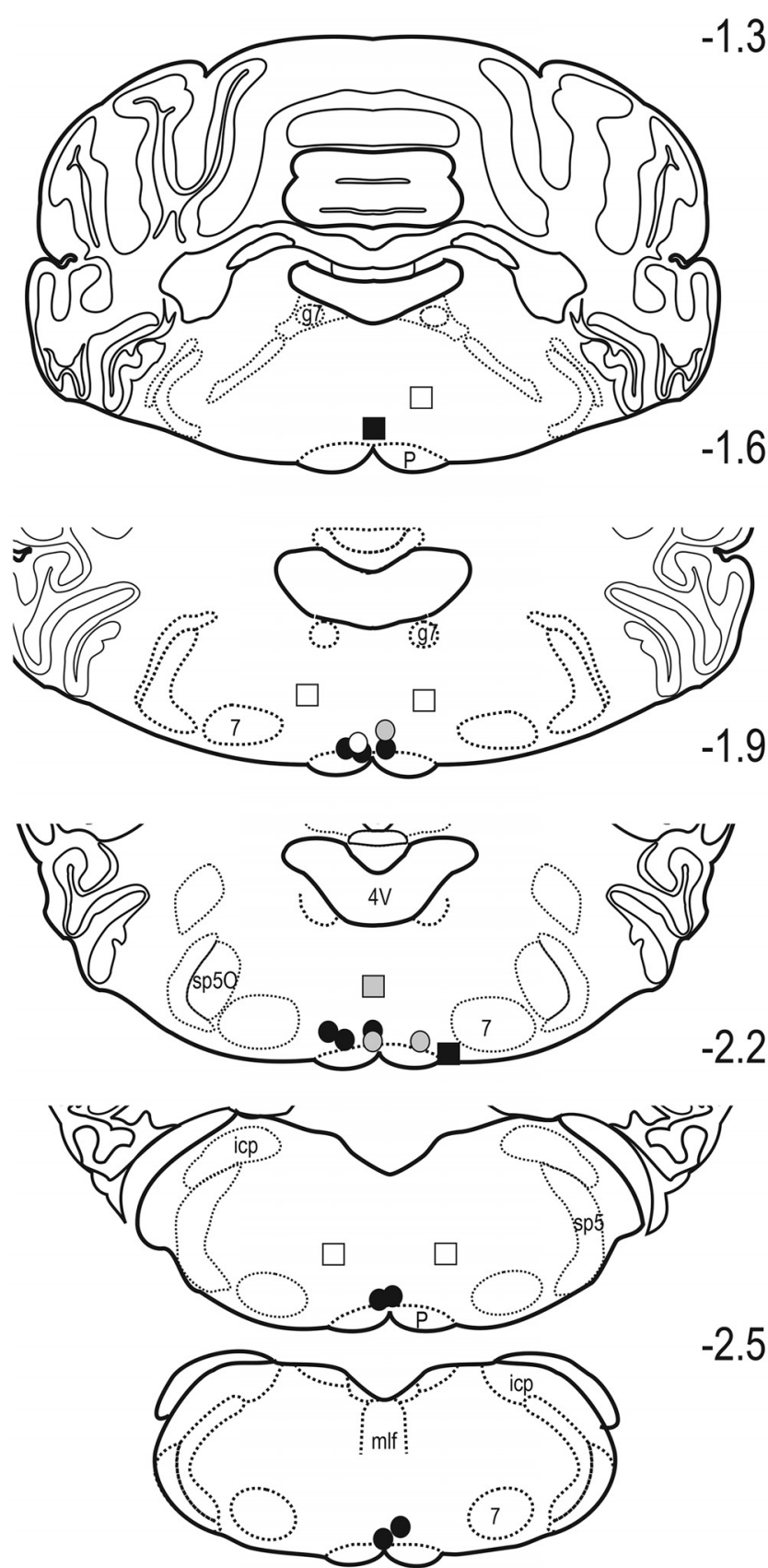

Fig. 2. Distribution of sites in the RVM of uninjured rats at which $4.11 \mathrm{ng}$ epibatidine was microinjected. The symbols encode the magnitude of the effect determined 10 min after microinjection. Gray and black circles, respectively, indicate that PWL was at least 2 and 3 SD greater than the mean baseline latency for the treatment group. Sites outside the RVM are indicated by similarly coded squares. Sites at which PWL changed by $<1$ SD are indicated by open symbols. $4 \mathrm{~V}$, fourth ventricle; g7, genu of the facial nerve; icp, inferior cerebellar peduncle; mlf, medial longitudinal fasciculus; $\mathrm{P}$, pyramid; sp50, spinal trigeminal nucleus pars oralis; sp5, spinal trigeminal tract; 7 , facial motor nucleus. Numbers indicate distance in millimeters from the interaural line.

Given that the findings at $4 \mathrm{~h}$ suggested alterations in the pharmacology of epibatidine, additional studies were conducted 2 weeks after CFA treatment. At this time (treat- ment $F_{(2,20)}=3.584, p=0.047$; time $F_{(5,100)}=38.528, p<$ 0.001 ; interaction $\left.F_{(10,100)}=1.238, p=0.276\right)^{n}$, challenge with $5 \mu \mathrm{g} \mathrm{DH} \beta \mathrm{E}$ only partially antagonized the antihyperalgesic effects of epibatidine at $10 \mathrm{~min}(p=0.044$ at 10 -min time point), and challenge with $1 \mu \mathrm{g}$ MLA was ineffective $(p=0.083$; Fig. $4 C)$. These findings suggest that the antihyperalgesic effect was not substantially mediated by $\alpha 4 \beta 2$ or $\alpha 7$ nAChRs. In the presence of $\mathrm{DH} \beta \mathrm{E}$ or MLA, epibatidine continued to lack antinociceptive efficacy in the contralateral hind paw (treatment $F_{(2,20)}=2.719, p=0.090$; time $F_{(5,100)}=$ $4.3991, p=0.001$; interaction $F_{(10,100)}=1.391, p=0.2195$; Fig. $4 D)^{\circ}$.

To assess the possible development of tonic nAChR activity after inflammatory injury, the effects of the antagonists by themselves were also examined in the RVM of rats that received an intraplantar injection of CFA 2 weeks earlier (Fig. 5A, B). As for the pharmacological challenge of epibatidine, the antagonists were microinjected $20 \mathrm{~min}$ before injection of saline at the same site so that their effects could be assessed at the same time. Heat hyperalgesia in the ipsilateral hind paw was unaffected by either $\mathrm{DH} \beta \mathrm{E}$ or MLA (treatment $F_{(2,17)}=0.287, p=0.754$; time $F_{(5,85)}=25.112, p<0.001$; interaction $F_{(10,85)}=0.576$, $p=0.829)^{\mathrm{p}}$ (Fig. 5A). Paw withdrawal latency in the contralateral, uninflamed hind paw was also unaffected by either antagonist (treatment $F_{(2,17)}=0.281, p=0.758$; time $F_{(5,85)}=3.364, p=0.008$; interaction $F_{(10,85)}=0.609$, $p=0.802)^{\mathrm{q}}($ Fig. $5 B)$. These data suggest that minimal, if any, tonic activation of $\alpha 4 \beta 2$ or $\alpha 7$ nAChRs in the RVM develops as a consequence of persistent inflammatory injury.

\section{Peripheral inflammatory injury does not alter the number or affinity of $\alpha \mathbf{4} \beta 2$ nAChRs in the RVM}

Initial experiments established optimal assay conditions. Association analysis demonstrated that the amount of $\left[{ }^{3} \mathrm{H}\right]$ epibatidine bound rapidly increased after radioligand addition, and steady-state binding was achieved after $\sim 2 \mathrm{~h}$ of incubation (data not shown). As such, a 3-h incubation time was selected for all subsequent experiments. The association constant $k_{\text {on }}$ was $1.056 \times 10^{9} \mathrm{M}^{-1}$. $\mathrm{min}^{-1}$. The amount of bound $\left[{ }^{3} \mathrm{H}\right]$ epibatidine began to decrease immediately after dissociation was induced by the addition of the competing ligand nicotine, and specific binding became negligible after $\sim 11 \mathrm{~h}$ (data not shown). The dissociation constant $k_{\text {off }}$ was $6.72 \times 10^{-3}$ per min. The binding affinity for epibatidine, $K_{d}=k_{\text {off }} / k_{\text {on }}$, was calculated to be $6.37 \mathrm{pm}$, consistent with values found in the literature (Houghtling et al., 1995; Whiteaker et al., 1998).

Fig. 6 illustrates representative saturation isotherms for $\left[{ }^{3} \mathrm{H}\right]$ epibatidine binding in RVM tissue from saline- and CFA-treated rats. In saline-treated rats, the $B_{\max }$ values ranged from 18.9 to $23.6 \mathrm{fmol} / \mathrm{mg}$ protein, and the $K_{d}$ values ranged from 9.8 to $13.7 \mathrm{pm}$, in good agreement with those calculated using kinetic parameters. Comparison of saturation binding in the RVM of saline- and CFA-treated rats indicated that neither $B_{\max }$ (treatment $F_{(1,16)}=0.024, p=0.878$; time $\mathrm{F}_{(2,16)}=2.050, p=0.160$; interaction $\left.F_{(2,16)}=0.168, p=0.847\right)^{r}$ nor $K_{d}$ (treatment $\mathrm{F}_{(1,16)}=0.362, p=0.968$; time $F_{(2,16)}=0.002, p=0.702$; 

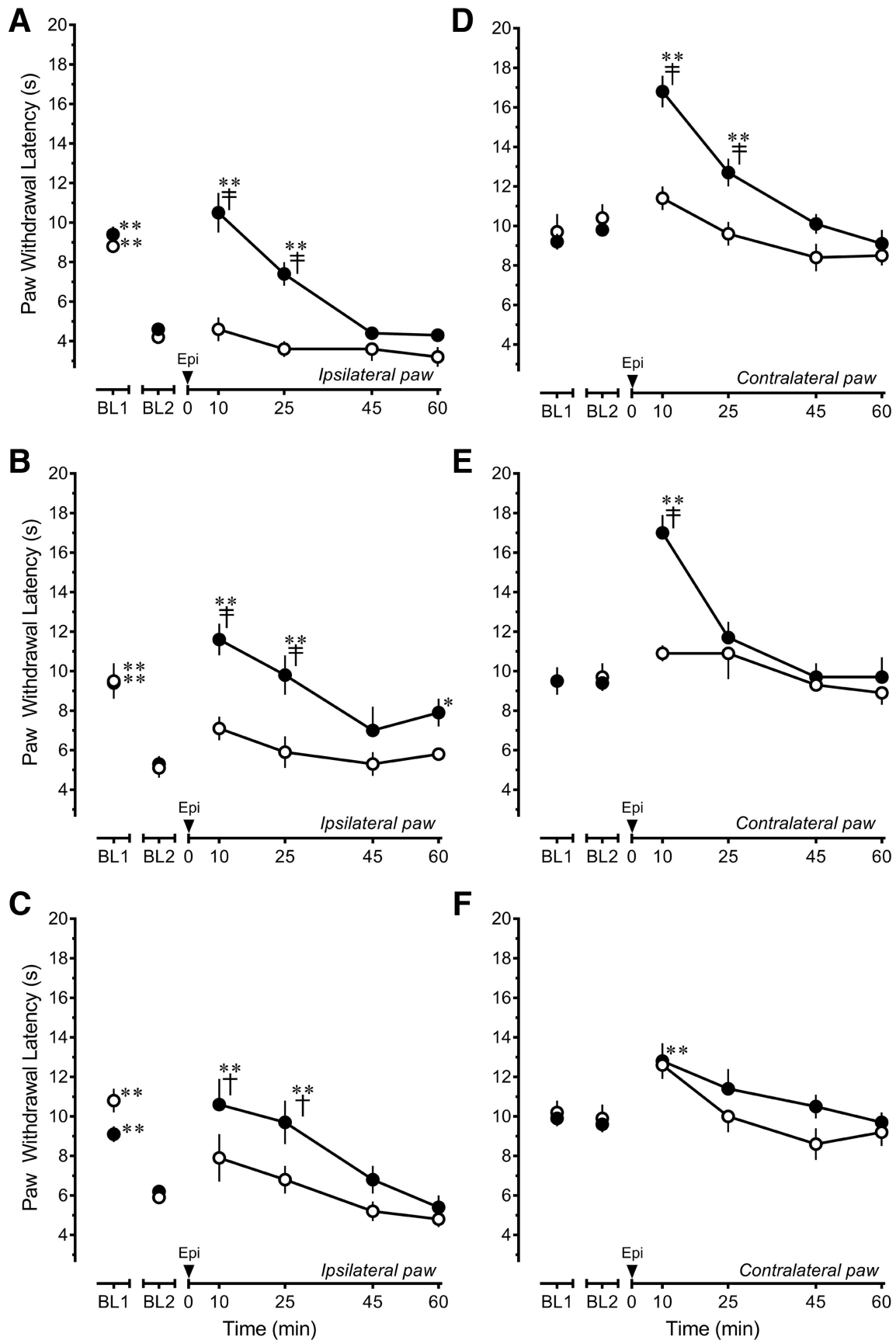

Fig. 3. The antihyperalgesic effect of epibatidine persists, whereas its antinociceptive effect declines in a time-dependent manner after peripheral inflammatory injury. Epibatidine $(\mathrm{Epi} ; 4.11 \mathrm{ng}, \mathbf{O})$ or saline $(\bigcirc)$ was microinjected in the rostral ventromedial medulla of rats $4 \mathrm{~h}(\boldsymbol{A}, \boldsymbol{D}$; saline $n=4$, epibatidine $n=10), 4 \mathrm{~d}(\boldsymbol{B}, \boldsymbol{E}$; saline $n=5$, epibatidine $n=8)$, or 2 weeks $(\boldsymbol{C}$, $\boldsymbol{F}$; saline $n=6$, epibatidine $n=11$ ) after intraplantar injection of CFA in the left hind paw. $\boldsymbol{A}-\boldsymbol{C}$, Ipsilateral, inflamed hind paw. $\boldsymbol{D}-\boldsymbol{F}$, Contralateral, uninflamed hind paw. Data are mean \pm SEM. BL1 refers to paw withdrawal latency before and BL2 refers to paw withdrawal latency after injection of CFA. $* p<0.05, * * p<0.01$ compared with BL2 values. ${ }^{\dagger} p<0.05,{ }^{\ddagger} p<0.01$ compared with saline control at the corresponding time point. Two-way repeated-measures ANOVA followed by Holm-Sidak test.

interaction $\left.F_{(2,16)}=0.067, p=0.935\right)^{\mathrm{s}}$ changed after peripheral inflammatory injury (Table 2 ).

The thickness of the injected hind paws in the cohort of CFA-treated rats used for the binding studies was significantly greater than that of the corresponding hind paw of saline-treated rats [ $4 \mathrm{~h}: 9.0 \pm 0.2$ vs. $5.8 \pm 0.1 ; 4$ d: $9.6 \pm$ 0.1 vs. $6.1 \pm 0.1 ; 2$ weeks: $10.3 \pm 0.2$ vs. $6.3 \pm 0.1 \mathrm{~mm}$
(4 h Welch-corrected $t=17.12, \mathrm{df}=10.59 ; 4 \mathrm{~d}$ Welchcorrected $t=22.54, \mathrm{df}=22.63 ; 2$ weeks Welch-corrected $t=16.44, \mathrm{df}=10.18, p<0.001$ for all three time points; $n=9-15$ at each time point) $\left.{ }^{t}\right]$ or the uninflamed, contralateral hind paws (data not shown). The thickness of the ipsilateral hind paw of saline-treated rats did not change at any time point (data not shown). 

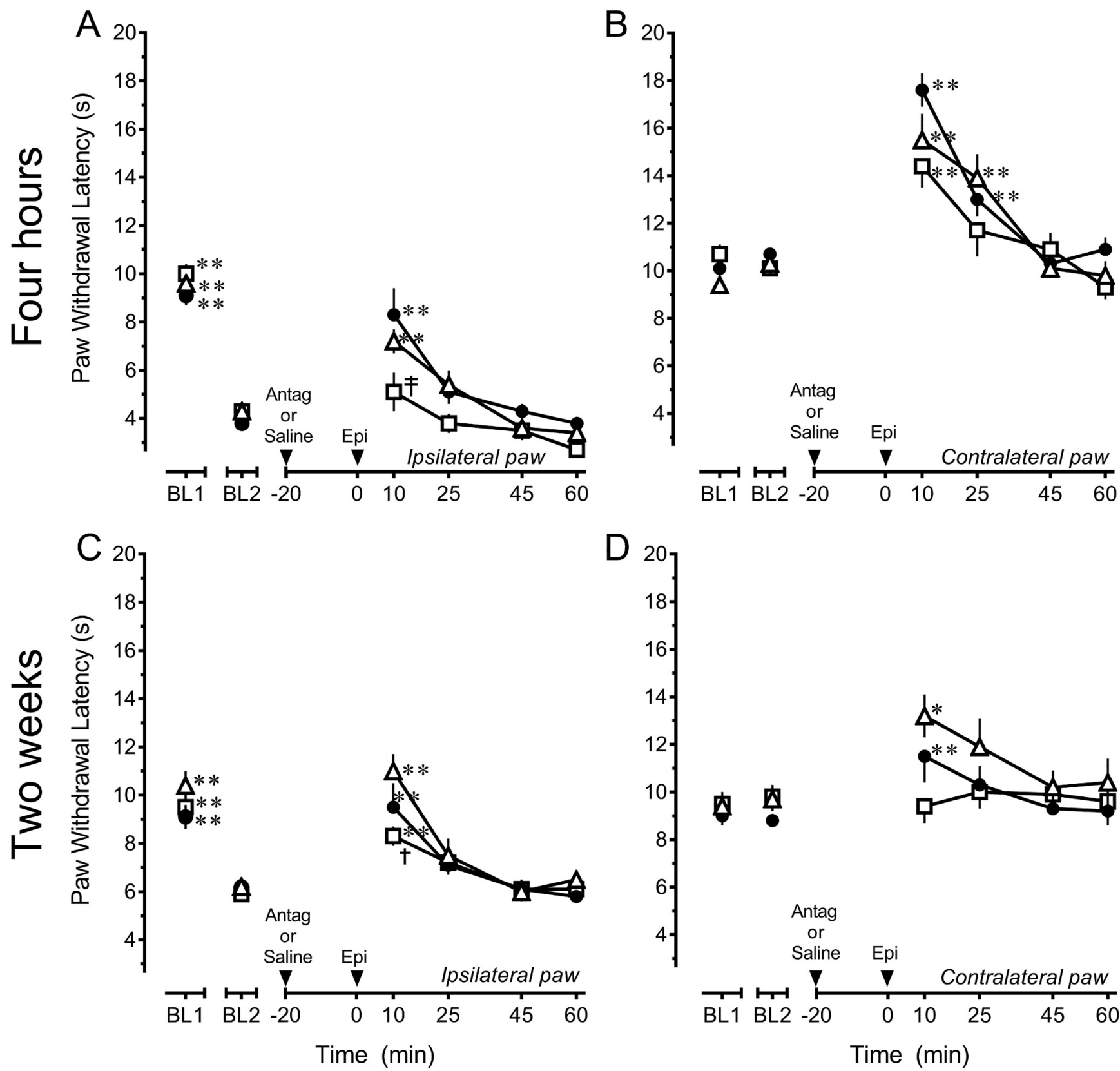

Fig. 4. Persistent inflammatory injury alters the mechanisms by which epibatidine modulates nociception in the rostral ventromedial medulla in a time-dependent manner. $\boldsymbol{A}$, Microinjection of $5 \mu \mathrm{g} \mathrm{DH} \beta \mathrm{E}(\square, n=8)$ completely antagonizes while $1 \mu \mathrm{g}$ MLA ( $\triangle, n=8)$ does not diminish the antihyperalgesic effect of $4.11 \mathrm{ng}$ epibatidine (Epi) in rats that received an intraplantar injection of CFA $4 \mathrm{~h}$ earlier compared to saline $(\boldsymbol{\bullet}, n=9)$. $\boldsymbol{B}$, Microinjection of $5 \mu \mathrm{g} \mathrm{DH} \beta \mathrm{E}(\square, n=8)$ or $1 \mu \mathrm{g} \mathrm{MLA}(\Delta, n=8)$ did not antagonize the increase in paw withdrawal latency of the contralateral hind paw in rats that received an intraplantar injection of CFA $4 \mathrm{~h}$ earlier compared to saline $(\bullet, n=9)$. $\boldsymbol{C}$, Microinjection of $5 \mu \mathrm{g} \mathrm{DH} \beta \mathrm{E}(\square, n=9)$ only partially antagonizes while $1 \mu \mathrm{g} \operatorname{MLA}(\Delta, n=5)$ does not diminish the antihyperalgesic effect of $4.11 \mathrm{ng}$ epibatidine in rats that received an intraplantar injection of CFA 2 weeks earlier compared to saline $(\boldsymbol{O}, n=9)$. $\boldsymbol{D}$, Microinjection of $5 \mu \mathrm{g} \mathrm{DH} \beta \mathrm{E}(\square, n=9)$ or $1 \mu \mathrm{g} \mathrm{MLA}(\Delta, n=5)$ before 4.11 ng epibatidine did not alter PWL of the contralateral hind paw in rats that received an intraplantar injection of CFA 2 weeks earlier compared to saline before 4.11 ng epibatidine $(\bullet, n=9)$. Data are mean \pm SEM. BL1 refers to paw withdrawal latency before and BL2 refers to paw withdrawal latency after injection of CFA. $* p<0.05, * * p<0.01$ compared with BL2 values. ${ }^{\dagger} p<0.05,{ }^{\ddagger} p<0.01$ compared with saline control at the corresponding time point. Two-way repeated-measures ANOVA followed by Holm-Sidak test.

\section{Discussion}

This study first confirmed that the RVM is an important site of action for the antinociceptive effects of $\alpha 4 \beta 2$ preferring nAChR agonists (Iwamoto, 1991; Bitner et al.,
1998; Curzon et al., 1998) and characterized the receptor through which epibatidine acts in uninjured rats. Subsequent experiments characterized the ramifications of persistent inflammatory pain on the actions of epibatidine. 

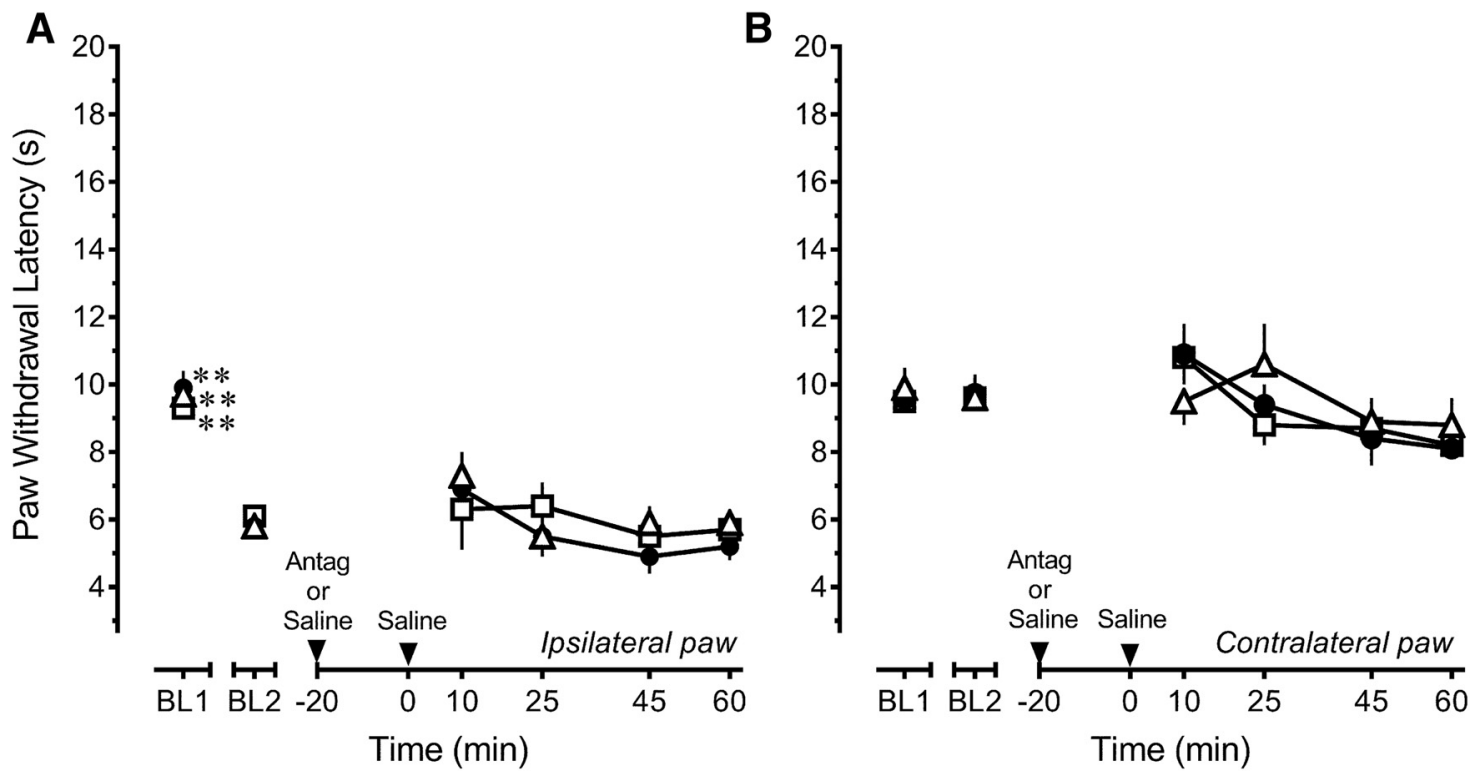

Fig. 5. Persistent inflammatory injury does not establish tonic nicotinic cholinergic signaling in the rostral ventromedial medulla. In rats that received an intraplantar injection of CFA 2 weeks earlier, microinjection of $5 \mu \mathrm{g} \mathrm{DH} \beta \mathrm{E}(\square, n=6)$ or $1 \mu \mathrm{g} \mathrm{MLA}(\triangle$, $n=6)$ did not alter either heat hyperalgesia in the ipsilateral, inflamed hind paw $(\boldsymbol{A})$ or antinociception in the contralateral, uninflamed hind paw $(B)$ compared to saline $(\bullet, n=8)$. Data are mean \pm SEM. BL1 refers to paw withdrawal latency before and BL2 refers to paw withdrawal latency after injection of CFA. $* * p<0.01$ compared with BL2 values. Two-way repeated-measures ANOVA followed by Holm-Sidak test.

Epibatidine retained its ability to alleviate heat hyperalgesia as long as 2 weeks after injury. Although mediated by $\alpha 4 \beta 2 \mathrm{nAChRs} 4 \mathrm{~h}$ after injury, by 2 weeks the antihyperalgesia was no longer substantially mediated by these receptors. Its antinociceptive effect, determined in the contralateral hind paw, was abolished in a time-dependent manner. Moreover, in contrast to naive rats, the antinociceptive effect was no longer mediated by $\alpha 4 \beta 2$

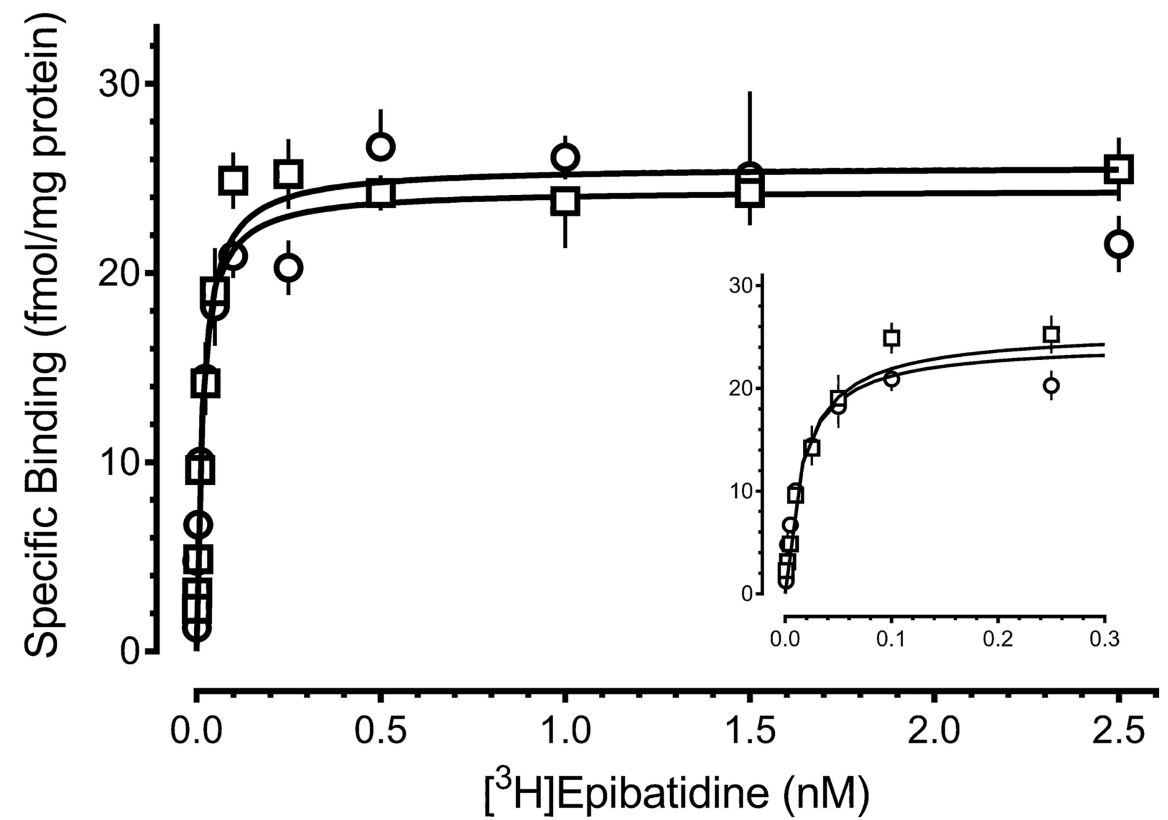

Fig. 6. Persistent inflammatory injury does not alter the number or affinity of $\alpha 4 \beta 2$ nicotinic cholinergic receptors in the rostral ventromedial medulla. Saturation isotherms for binding of $\left[{ }^{3} \mathrm{H}\right]$ epibatidine to membrane homogenates of the rostral ventromedial medulla of rats $4 \mathrm{~h}$ after intraplantar injection of saline $(\square)$ or CFA $(\circ)$ in the hind paw. Symbols represent the mean \pm SEM. of triplicate samples. Results from a single representative experiment are illustrated. Specific binding was determined by subtracting nonspecific binding from total binding at each of these concentrations. Specific binding data were fitted using nonlinear regression in GraphPad Prism. Inset, Magnified view of curves at low radioligand concentrations. 
Table 2. Persistent inflammation does not alter the number $\left(B_{\max }\right)$ or affinity $\left(K_{d}\right)$ of $\alpha 4 \beta 2$ nicotinic acetylcholine receptors in the rostral ventromedial medulla.

\begin{tabular}{lcc}
\hline Treatment & $B_{\text {max }}, \mathrm{fmol} / \mathrm{mg}$ protein & $K_{d}, \mathrm{pM}$ \\
$4 \mathrm{~h}$ & $22.5 \pm 2.0$ & $12.5 \pm 2.4$ \\
$\quad$ Saline & $23.6 \pm 0.5$ & $13.7 \pm 0.7$ \\
$\quad$ CFA & & \\
$4 \mathrm{~d}$ & $19.4 \pm 2.1$ & $12.5 \pm 4.2$ \\
$\quad$ Saline & $20.0 \pm 1.4$ & $12.3 \pm 1.6$ \\
CFA & & \\
2 weeks & $20.0 \pm 1.1$ & $11.1 \pm 2.0$ \\
Saline & $18.9 \pm 2.6$ & $9.8 \pm 3.6$ \\
CFA & &
\end{tabular}

Saturation isotherms were generated for the binding of $\left[{ }^{3} \mathrm{H}\right]$ epibatidine in membrane homogenates prepared from rats $4 \mathrm{~h}, 4 \mathrm{~d}$, or 2 weeks after intraplantar injection of saline or CFA. Values represent the mean \pm SEM. of three to five independent experiments. Two-way ANOVA (treatment $\times$ time) for each binding parameter identified no statistical differences.

nAChRs as early as $4 \mathrm{~h}$ after CFA. These changes occurred in the absence of changes in the $B_{\max }$ or $K_{d}$ of $\alpha 4 \beta 2$ nAChRs in the RVM.

\section{Pharmacology of the antinociceptive effect of epibatidine in the RVM of uninjured rats}

In uninjured rats, microinjection of epibatidine in the RVM dose-dependently increased PWL. As reported (Curzon et al., 1998), the slope of the dose-response curve was relatively shallow and may reflect rapid desensitization of $\alpha 4 \beta 2 \mathrm{nAChRs} \mathrm{(Zhang} \mathrm{et} \mathrm{al.,} \mathrm{2012).} \mathrm{Also,} \mathrm{the}$ first measure of PWL was not made until 10 min after microinjection to minimize any effects of handling. Thus, both the potency and efficacy of epibatidine may be underestimated here.

In terms of affinity and potency, epibatidine is $\sim 300$ fold selective for $\alpha 4 \beta 2$ over $\alpha 7$ nAChRs (Wonnacott and Barik, 2007). It was used as a pharmacological probe in this study because it is several orders of magnitude more potent than nicotine, which is less selective for $\alpha 4 \beta 2$ over $\alpha 7$ nAChRs (Wonnacott and Barik, 2007). The ability of $\mathrm{DH} \beta \mathrm{E}$ to completely block effects of epibatidine in the RVM reaffirms (Curzon et al., 1998) that the principal mechanism of action of epibatidine in the RVM entails activation of heteromeric nAChRs, principally $\alpha 4 \beta 2$. This subtype accounts for $70 \%-90 \%$ of $\left[{ }^{3} \mathrm{H}\right]$ nicotine binding sites in the brain (Daly, 2005; Wonnacott and Barik, 2007; Marks et al., 2010). However, in mouse brain, one-third of the low-affinity epibatidine binding sites are attributed to $\alpha 7$ nAChRs (Marks et al., 2010). The effects of epibatidine were therefore also challenged with the $\alpha 7 \mathrm{nAChR}$ antagonist, MLA. Interestingly, MLA partially attenuated the effect of epibatidine. Autoradiography has detected only very low levels of $\alpha 7 \mathrm{nAChRs}$ in the RVM (Mugnaini et al., 2002; Tribollet et al., 2004; Maier et al., 2011; but see Clarke et al., 1985). Thus, $\alpha 7$ nAChRs may make a minor contribution to epibatidine-induced antinociception in the RVM in the uninjured state. Given that $\alpha 7 \mathrm{nAChRs}$ are expressed in several pain modulatory nuclei that project to the RVM, such as the periaqueductal gray and amygdala (Clarke et al., 1985), systemically administered $\alpha 7 \mathrm{nAChR}$ agonists may be able to indirectly engage the neural circuitry of the RVM.

MLA also has nanomolar affinity for $\alpha 6 \beta 2$ nAChRs, albeit about 30-fold less than for $\alpha 7$ nAChRs (Mogg et al., 2002; Wonnacott and Barik, 2007). The ability of MLA to partially attenuate the effects of epibatidine may therefore also reflect a contribution of $\alpha 6$-containing $\mathrm{nAChRs}$ such as $\alpha 3 / \alpha 6 \beta 2 \beta 3$. The distribution of $\alpha 6$-containing nAChRs in the CNS is highly restricted (Picciotto et al., 2001), and the majority of studies have focused on their role in the presynaptic facilitation of dopamine release in the reward pathways (Yang et al., 2009). However, $\alpha 6$-containing nAChRs have been implicated in nicotine-induced release of norepinephrine in the hippocampus (Azam et al., 2010), and high levels of $\alpha 6$ mRNA are present in the locus coeruleus (Le Novère et al., 1996; Léna et al., 1999). Noradrenergic afferents to the RVM modulate the activity of bulbospinal pain inhibitory and facilitatory neurons in the RVM (Hammond et al., 1980; Sagen and Proudfit, 1985; Haws et al., 1990; Bie et al., 2003). Thus, it is possible that a component of epibatidine's effects could be mediated by actions at $\alpha 6$-containing nAChRs (Champtiaux et al., 2002) situated on noradrenergic terminals in the RVM.

\section{Inflammatory injury changes the mechanism by which epibatidine alleviates hyperalgesia and diminishes its antinociceptive efficacy}

Numerous studies have reported that agonists for $\alpha 4 \beta 2, \alpha 7$, or $\alpha 3 / \alpha 6 \beta 2 \beta 3 \mathrm{nAChRs}$ alleviate hyperalgesia when systemically administered in a number of inflammatory models including CFA, formalin, or carrageenan (Kesingland et al., 2000; Medhurst et al., 2008; Feuerbach et al., 2009; Gao et al., 2010; Zhu et al., 2011; AISharari et al., 2012; Munro et al., 2012; Nirogi et al., 2013). Much less is known about the actions of nAChR agonists selective for receptors containing $\alpha 5$ and $\alpha 6$ subunits, in part because of the absence of selective full agonists. One study has correlated the antinociceptive potency of $\alpha 4 \beta 2$ $\mathrm{nAChR}$ agonists in the formalin test to their potency to desensitize this receptor, particularly when it contains an $\alpha 5$ subunit (Zhang et al., 2012), and another demonstrated that the anti-allodynic effect of nicotine in the formalin test was dependent on the presence of an $\alpha 5$ subunit (Bagdas et al., 2015). With respect to the $\alpha 6$ subunit, deletion of this subunit greatly diminished the antihyperalgesic effect of nicotine in CFA-treated mice (Wieskopf et al., 2015).

Studies of the antihyperalgesic effects of nAChR agonists have rarely characterized efficacy or potency as a function of time after injury or probed pharmacological specificity any later than $4 \mathrm{~d}$ after injury, nor have they investigated actions in supraspinal pain modulatory circuitry. This study demonstrated that epibatidine retained its antihyperalgesic effects for as long as 2 weeks after inflammatory injury. In the period immediate to injury, its antihyperalgesic effect was completely antagonized by $\mathrm{DH} \beta \mathrm{E}$, consistent with activation of $\alpha 4 \beta 2 \mathrm{nAChRs}$. However, when reassessed 2 weeks later, epibatidine's antihyperalgesic effect was only partially antagonized by $\mathrm{DH} \beta \mathrm{E}$. Of note, MLA did not antagonize the antihyperal- 
gesic effects of epibatidine at either time. The present findings point to a striking change in the mechanism by which epibatidine alleviates hyperalgesia to one that does not involve $\alpha 7$ or $\alpha 3 / \alpha 6 \beta 2 \beta 3$, and only minimally involves $\alpha 4 \beta 2$ nAChRs, in a key pain modulatory pathway.

In contrast to its antihyperalgesic effects, epibatidine's antinociceptive efficacy progressively declined such that it was without effect by 2 weeks. These findings are consistent with the proposal that chronic pain conditions lead to a loss of the analgesic efficacy of nicotine. Moreover, as early as $4 \mathrm{~h}$ of injury, the antinociceptive effect of epibatidine was no longer mediated by $\alpha 4 \beta 2$ or $\alpha 7$ nAChRs. Whether this is due to changes in subunit composition, such as a downregulation of $\alpha 5$ subunits that assemble with $\alpha 4 \beta 2$ subunits, remains to be determined.

\section{Inflammatory injury and $\alpha 4 \beta 2 \mathrm{nAChRs}$ in the RVM}

The few studies that have assessed how persistent pain states alter the expression of nAChRs in the CNS confined their analysis to peripheral nerve injury. Spinal nerve ligation did not alter the $B_{\max }$ or $K_{d}$ of epibatidine binding sites in the dorsal horn, but an increase in the ability of nicotine to displace epibatidine suggested a change in receptor subtype (Young et al., 2008). Partial ligation of the sciatic nerve increased binding to $\alpha 4 \beta 2 \mathrm{nAChRs}$ in the thalamus (Ueda et al., 2010). However, it did not change epibatidine binding in the RVM, as was also observed here with CFA. Chronic constriction injury decreased $\beta 4$ subunits in hippocampus, thalamus, and spinal cord (Xanthos et al., 2015).

In contrast, inflammatory injury did not change the affinity or number of $\alpha 4 \beta 2 \mathrm{nAChRs}$ in the RVM. A decrease in the number or affinity of $\alpha 4 \beta 2$ nAChRs therefore does not appear to be responsible for the loss of antinociceptive efficacy or contribute to the change in receptors that mediate its antihyperalgesic effects. However, several caveats should be noted. Changes in receptor number or subunit composition limited to subpopulations of RVM neurons may not have been detected by radioligand binding in tissue homogenates. An example would be a downregulation of $\alpha 5$ subunits, which can affiliate with $\alpha 4 \beta 2$ nAChRs and contribute to the antinociceptive effects of nicotine (Ramirez-Latorre et al., 1996; Jackson et al., 2010; but see Xanthos et al., 2015). Finally, evidence is accruing for an interaction of nAChRs and G-proteins (Kabbani et al., 2013) such that alterations in subcellular signaling pathways downstream of the receptor may play a role.

\section{Effect of inflammatory injury on pain modulatory pathways and implications for nicotinic modulation of nociception}

Inflammatory injury may alter the affinity, number, and subtypes of nAChRs through which agonists or endogenously release acetylcholine act to modulate nociception. However, it is also possible that the antihyperalgesic and antinociceptive effects of $\mathrm{nAChR}$ agonists are altered independently of changes in the nAChR, as occurred here in the RVM. For example, presynaptic nAChRs promote neurotransmitter release (Picciotto et al., 2012). The antinociceptive and antihyperalgesic effects of nAChR agonists may therefore be altered secondary to injury-induced plasticity in other neurotransmitter systems whose release nAChR agonists promote, e.g., a reduction in terminal content of the neurotransmitter or a downregulation of its corresponding receptor. For example, persistent inflammatory injury enhances the antihyperalgesic or antinociceptive actions of opioid, $\alpha$-amino-3-hydroxy-5-methyl-4-isoxazolepropionic acid (AMPA), and $\mathrm{N}$-methyl-D-aspartate receptor agonists in the RVM (Hurley and Hammond, 2000; Guan et al., 2002, 2003, 2004). A facilitation of opioid peptide or glutamate release in the RVM would be inconsistent with the loss of antinociceptive efficacy of epibatidine. However, prior activation of $\alpha 4 \beta 2$ nAChRs in synaptosomes of the nucleus trigeminal caudalis is reported to increase internalization and functionally downregulate AMPA receptors with a concomitant decrease in excitatory amino acid release (Samengo et al., 2015). If operative in the RVM, an epibatidine-induced decrease in functional AMPA receptors could contribute to a decrement in antinociception. Peripheral stimulation during chronic inflammatory pain states is also associated with release of two pronociceptive neurotransmitters in the RVM: GABA (Gillbert and Franklin, 2001) and substance $P$ (Hamity et al., 2014). Epibatidine-induced augmentation of GABA or substance $P$ release may also contribute to the loss of antinociception. The development of analgesics based on activation of nAChRs for the relief of persistent pain will require a better understanding of how peripheral injury affects the expression of different nAChR subtypes in specific sites, as well how it alters the activity and function of the neurotransmitter systems that these receptors engage.

\section{Potential ramifications for development of positive allosteric modulators as analgesics}

Positive allosteric modulators (PAMs) for $\alpha 4 \beta 2$ and $\alpha 7$ nAChRs are a promising approach to potentiate endogenously released acetylcholine or low doses of orthosteric agonists and thereby circumvent the narrow therapeutic index of orthosteric agonists (Lee et al., 2011; Nirogi et al., 2013). Both $\alpha 4 \beta 2$ and $\alpha 7$ nAChR PAMs are efficacious in certain preclinical pain models (Zhu et al., 2011; Freitas et al., 2013; Bagdas et al., 2016; but see Gao et al., 2010). When administered alone, the efficacy of PAMs is dependent on release of endogenous acetylcholine. In this study, microinjection of $D H \beta E$ or MLA did not alter PWL in either uninjured rats or CFA-treated rats. These data suggest that there is little to no tonic release of acetylcholine in the RVM that would engage $\alpha 4 \beta 2$ or $\alpha 7 \mathrm{nAChRs}$ and that the RVM would be an unlikely site of action for the analgesic effects of systemically administered PAMs.

\section{Conclusion}

A loss of nAChR agonist efficacy has not been modeled in the preclinical literature to date, and no studies have compared antinociceptive efficacy between uninjured and persistent pain states. At first glance, the loss of antinociceptive efficacy in the face of the retention of antihyperalgesic efficacy appears puzzling. The former is compatible with the hypothesis that persistent pain leads to a loss of nicotine's analgesic efficacy, but the latter is not. Several possibilities merit consideration and indicate potential avenues of future investigation. First, although the antihyperalgesic efficacy of 
epibatidine was retained in these experiments, it is not known whether this is the clinical experience. The extant literature principally concerns nicotine's effects in the acute and postoperative pain setting. Indeed, the continued presence of chronic pain in smokers and the positive correlation between severity of pain and smoking would suggest that it is not (Bakhshaie et al., 2016). Second, reward and pain modulatory pathways are intimately linked (Navratilova and Porreca, 2014). It remains to be determined whether persistent pain also alters the expression of nAChRs in reward pathways or diminishes the rewarding effects of nicotine, which could drive those with chronic pain to smoke more. Finally, these differential effects also suggest that the RVM circuitry that mediates antihyperalgesia and antinociception can be dissociated. In summary, the present findings are the first evidence in a preclinical model of persistent pain of adaptive changes in a critical nucleus that result in an eventual loss of antinociceptive efficacy of a nAChR agonist and a change in the mechanism by which it produces antihyperalgesia. The exact nature of these changes, how they affect the actions of nicotine and other more subtype selective nAChR agonists in the RVM, as well as systemically administered nicotine, are the focus of ongoing investigation.

\section{References}

AISharari SD, Carroll FI, Mclntosh JM, Damaj MI (2012) The antinociceptive effects of nicotinic partial agonists varenicline and sazetidine-A in murine acute and tonic pain models. J Pharmacol Exp Ther 342:742-749. CrossRef Medline

Azam L, Maskos U, Changeux JP, Dowell CD, Christensen S, De Biasi M, Mclntosh JM (2010) Conotoxin BulA[T5A;P6O]: a novel ligand that discriminates between $\alpha 6 \beta 4$ and $\alpha 6 \beta 2$ nicotinic acetylcholine receptors and blocks nicotine-stimulated norepinephrine release. FASEB J 24:5113-5123. CrossRef

Bagdas D, AISharari SD, Freitas K, Tracy M, Damaj MI (2015) The role of alpha5 nicotinic acetylcholine receptors in mouse models of chronic inflammatory and neuropathic pain. Biochem Pharmacol 590-600. CrossRef

Bagdas D, Wilkerson JL, Kulkarni A, Toma W, AISharari S, Gul Z, Lichtman AH, Papke RL, Thakur GA, Damaj MI (2016) The alpha7 nicotinic receptor dual allosteric agonist and positive allosteric modulator GAT107 reverses nociception in mouse models of inflammatory and neuropathic pain. Br J Pharmacol 173:2506-2520. CrossRef Medline

Bakhshaie J, Ditre JW, Langdon KJ, Asmundson GJ, Paulus DJ, Zvolensky MJ (2016) Pain intensity and smoking behavior among treatment seeking smokers. Psychiatr Res 237:67-71. CrossRef Medline

Bannon AW, Decker MW, Holladay MW, Curzon P, Donnelly-Roberts D, Puttfarcken PS, Bitner RS, Diaz A, Dickenson AH, Porsolt RD, Williams M, Arneric SP (1998) Broad-spectrum, non-opioid analgesic activity by selective modulation of neuronal nicotinic acetylcholine receptors. Science 279:77-81. Medline

Bie B, Fields HL, Williams JT, Pan ZZ (2003) Roles of $\alpha 1$ - and $\alpha 2$-adrenoceptors in the nucleus raphe magnus in opioid analgesia and opioid abstinence-induced hyperalgesia. J Neurosci 23: 7950-7957.

Bitner RS, Nikkel AL, Curzon P, Arneric SP, Bannon AW, Decker MW (1998) Role of the nucleus raphe magnus in antinociception produced by ABT-594: immediate early gene responses possibly linked to neuronal nicotinic acetylcholine receptors on serotonergic neurons. J Neurosci 18:5426-5432. Medline

Centers for Disease Control and Prevention (2004) The Health Consequences of Smoking: A Report of the Surgeon General, in (Services USDoHaH ed), Office on Smoking and Health, National
Center for Chronic Disease Prevention and Health Promotion, Atlanta, GA.

Centers for Disease Control and Prevention (2010) Surgeon General's Report-How Tobacco Smoke Causes Disease: The Biology and Behavioral Basis for Smoking-Attributable Disease. Office on Smoking and Health, National Center for Chronic Disease Prevention and Health Promotion, Atlanta, GA.

Champtiaux N, Han Z-Y, Bessis A, Rossi FM, Zoli M, Marubio L, Mclntosh JM, Changeux J-P (2002) Distribution and pharmacology of $\alpha 6$-containing nicotinic acetylcholine receptors analyzed with mutant mice. J Neurosci 22:1208-1217. Medline

Champtiaux N, Kalivas PW, Bardo MT (2006) Contribution of dihydro-beta-erythroidine sensitive nicotinic acetylcholine receptors in the ventral tegmental area to cocaine-induced behavioral sensitization in rats. Behav Brain Res 168:120-126. CrossRef Medline

Clarke PB, Schwartz RD, Paul SM, Pert CB, Pert A (1985) Nicotinic binding in rat brain: autoradiographic comparison of $\left[{ }^{3} \mathrm{H}\right]$ acetylcholine, $\left[{ }^{3} \mathrm{H}\right]$ nicotine, and $\left[{ }^{125} \mathrm{I}\right]-\alpha$-bungarotoxin. J Neurosci 5:1307-1315.

Curzon P, Nikkel AL, Bannon AW, Arneric SP, Decker MW (1998) Differences between the antinociceptive effects of the cholinergic channel activators A-85380 and ( \pm )-epibatidine in rats. J Pharmacol Exp Ther 287:847-853. Medline

Daly JW (2005) Nicotinic agonists, antagonists, and modulators from natural sources. Cell Mol Neurobiol 25:513-552. CrossRef Medline

Decker MW, Curzon P, Holladay MW, Nikkel AL, Bitner RS, Bannon AW, Donnelly-Roberts DL, Puttfarcken PS, Kuntzweiler TA, Briggs CA, Williams M, Arneric SP (1998) The role of neuronal nicotinic acetylcholine receptors in antinociception: effects of ABT-594. J Physiol Paris 92:221-224. Medline

Decker MW, Meyer MD, Sullivan JP (2001) The therapeutic potential of nicotinic acetylcholine receptor agonists for pain control. Expert Opin Investig Drugs 10:1819-1830. CrossRef Medline

Ditre JW, Brandon TH (2008) Pain as a motivator of smoking: effects of pain induction on smoking urge and behavior. J Abnorm Psychol 117:467-472. CrossRef Medline

Ditre JW, Brandon TH, Zale EL, Meagher MM (2011) Pain, nicotine, and smoking: research findings and mechanistic considerations. Psychol Bull 137:1065-1093. CrossRef Medline

Ditre JW, Heckman BW, Zale EL, Kosiba JD, Maisto SA (2016) Acute analgesic effects of nicotine and tobacco in humans: a metaanalysis. Pain 157:1373-1381. CrossRef Medline

Feuerbach D, Lingenhoehl K, Olpe HR, Vassout A, Gentsch C, Chaperon F, Nozulak J, Enz A, Bilbe G, McAllister K, Hoyer D (2009) The selective nicotinic acetylcholine receptor alpha7 agonist JN403 is active in animal models of cognition, sensory gating, epilepsy and pain. Neuropharmacology 56:254-263. CrossRef Medline

Freitas K, Ghosh S, Ivy Carroll F, Lichtman AH, Imad Damaj M (2013) Effects of alpha7 positive allosteric modulators in murine inflammatory and chronic neuropathic pain models. Neuropharmacology 65:156-164. CrossRef Medline

Gao B, Hierl M, Clarkin K, Juan T, Nguyen H, Valk M, Deng H, Guo W, Lehto SG, Matson D, McDermott JS, Knop J, Gaida K, Cao L, Waldon D, Albrecht BK, Boezio AA, Copeland KW, Harmange JC, Springer SK, Malmberg AB, McDonough SI (2010) Pharmacological effects of nonselective and subtype-selective nicotinic acetylcholine receptor agonists in animal models of persistent pain. Pain 149:33-49. CrossRef Medline

Gilbert AK, Franklin KB (2001) GABAergic modulation of descending inhibitory systems from the rostral ventromedial medulla (RVM). Dose-response analysis of nociception and neurological deficits. Pain 90:25-36. Medline

Guan Y, Guo W, Robbins MT, Dubner R, Ren K (2004) Changes in AMPA receptor phosphorylation in the rostral ventromedial medulla after inflammatory hyperalgesia in rats. Neurosci Lett 366: 201-205. CrossRef Medline 
Guan Y, Guo W, Zou SP, Dubner R, Ren K (2003) Inflammationinduced upregulation of AMPA receptor subunit expression in brain stem pain modulatory circuitry. Pain 104:401-413. Medline

Guan Y, Terayama R, Dubner R, Ren K (2002) Plasticity in excitatory amino acid receptor-mediated descending pain modulation after inflammation. J Pharmacol Exp Ther 300:513-520. Medline

Hamity MV, Walder RY, Hammond DL (2014) Increased neuronal expression of neurokinin-1 receptor and stimulus-evoked internalization of the receptor in the rostral ventromedial medulla of the rat after peripheral inflammatory injury. J Comp Neur 522:3037-3051. CrossRef Medline

Hamity MV, White SR, Hammond DL (2010) Effects of neurokinin-1 receptor agonism and antagonism in the rostral ventromedial medulla of rats with acute or persistent inflammatory nociception. Neuroscience 165:902-913. CrossRef Medline

Hammond DL, Levy RA, Proudfit HK (1980) Hypoalgesia following microinjection of noradrenergic antagonists in the nucleus raphe magnus. Pain 9:85-101. Medline

Haws CM, Heinricher MM, Fields HL (1990) Alpha-adrenergic receptor agonists, but not antagonists, alter the tail-flick latency when microinjected into the rostral ventromedial medulla of the lightly anesthetized rat. Brain Res 533:192-195. CrossRef

Heinricher MM, Tavares I, Leith JL, Lumb BM (2009) Descending control of nociception: Specificity, recruitment and plasticity. Brain Res Rev 60:214-225. CrossRef Medline

Hong D, Conell-Price J, Cheng S, Flood P (2008) Transdermal nicotine patch for postoperative pain management: a pilot doseranging study. Anesth Analg 107:1005-1010. CrossRef Medline

Hooten WM, Shi Y, Gazelka HM, Warner DO (2011) The effects of depression and smoking on pain severity and opioid use in patients with chronic pain. Pain 152:223-229. CrossRef Medline

Houghtling R, Dávila-García M, Kellar K (1995) Characterization of $( \pm)\left[{ }^{3} \mathrm{H}\right]$ epibatidine binding to nicotinic cholinergic receptors in rat and human brain. Mol Pharmacol 48:280-287. Medline

Hurley RW, Hammond DL (2000) The analgesic effects of supraspinal $\mu \mathrm{u}$ and Selta opioid receptor agonists are potentiated during persistent inflammation. J Neurosci 20:1249-1259. Medline

Hurley RW, Hammond DL (2001) Contribution of endogenous enkephalins to the enhanced analgesic effects of supraspinal $\mu \mathrm{u}$ opioid receptor agonists after inflammatory injury. J Neurosci 21: 2536-2545. Medline

Hurst R, Rollema H, Bertrand D (2013) Nicotinic acetylcholine receptors: from basic science to therapeutics. Pharmacol Ther 137:2254. CrossRef Medline

Institute of Medicine (2011) Relieving Pain in America: A Blueprint for Transforming Prevention, Care, Education, and Research. Washington, D.C. National Academies Press.

Iwamoto ET (1991) Characterization of the antinociception induced by nicotine in the pedunculopontine tegmental nucleus and the nucleus raphe magnus. J Pharmacol Exp Ther 257:120-133. Medline

Jackson KJ, Marks MJ, Vann RE, Chen X, Gamage TF, Warner JA, Damaj MI (2010) Role of $\alpha 5$ nicotinic acetylcholine receptors in pharmacological and behavioral effects of nicotine in mice. $J$ Pharmacol Exp Ther 334:137-146. CrossRef Medline

Jones PG, Dunlop J (2007) Targeting the cholinergic system as a therapeutic strategy for the treatment of pain. Neuropharmacology 53:197-206. CrossRef Medline

Kabbani N, Nordman JC, Corgiat BA, Veltri DP, Shehu A, Seymour VA, Adams DJ (2013) Are nicotinic acetylcholine receptors coupled to $G$ proteins?. Bioessays 35:1025-1034. CrossRef

Kesingland AC, Gentry CT, Panesar MS, Bowes MA, Vernier JM, Cube R, Walker K, Urban L (2000) Analgesic profile of the nicotinic acetylcholine receptor agonists, (+)-epibatidine and ABT-594 in models of persistent inflammatory and neuropathic pain. Pain 86:113-118. CrossRef

Laviolette SR, van der Kooy D (2003) The motivational valence of nicotine in the rat ventral tegmental area is switched from rewarding to aversive following blockade of the $\alpha 7$-subunit-containing nicotinic acetylcholine receptor. Psychopharmacology (Berl) 166: 306-313. CrossRef

Le Novère N, Zoli M, Changeux J-P (1996) Neuronal nicotinic receptor a6 subunit mRNA is selectively concentrated in catecholaminergic nuclei of the rat brain. Eur J Neurosci 8:2428-2439. Medline

Lee CH, Zhu C, Malysz J, Campbell T, Shaughnessy T, Honore P, Polakowski J, Gopalakrishnan M (2011) $4 \beta 2$ neuronal nicotinic receptor positive allosteric modulation: an approach for improving the therapeutic index of $\alpha 4 \beta 2 \mathrm{nAChR}$ agonists in pain. Biochem Pharmacol 82:959-966. CrossRef

Léna $C$, de Kerchove D'Exaerde A, Cordero-Erausquin M, Le Novère N, del Mar Arroyo-Jimenez M, Changeux JP (1999) Diversity and distribution of nicotinic acetylcholine receptors in the locus ceruleus neurons. Proc Natl Acad Sci U S A 96:12126-12131. Medline

Maier DL, Hill G, Ding M, Tuke D, Einstein E, Gurley D, Gordon JC, Bock MJ, Smith JS, Bialecki R, Eisman M, Elmore CS, Werkheiser JL (2011) Pre-clinical validation of a novel alpha-7 nicotinic receptor radiotracer, $\left[{ }^{3} \mathrm{H}\right] \mathrm{AZ}$ 11637326: target localization, biodistribution and ligand occupancy in the rat brain. Neuropharmacology 61: 161-171. CrossRef

Marks MJ, Laverty DS, Whiteaker P, Salminen O, Grady SR, Mclntosh JM, Collins AC (2010) John Daly's compound, epibatidine, facilitates identification of nicotinic receptor subtypes. J Mol Neurosci 40:96-104. CrossRef Medline

Medhurst SJ, Hatcher JP, Hille CJ, Bingham S, Clayton NM, Billinton A, Chessell IP (2008) Activation of the alpha7-nicotinic acetylcholine receptor reverses complete freund adjuvant-induced mechanical hyperalgesia in the rat via a central site of action. J Pain 9:580-587. CrossRef

Millan MJ (2002) Descending control of pain. Prog Neurobiol 66:355474. Medline

Mogg AJ, Whiteaker P, Mclntosh JM, Marks M, Collins AC, Wonnacott $S$ (2002) Methyllycaconitine is a potent antagonist of $\alpha$ lphaconotoxin-MII-sensitive presynaptic nicotinic acetylcholine receptors in rat striatum. J Pharmacol Exp Ther 302:197-204. CrossRef

Mugnaini M, Tessari M, Tarter G, Merlo Pich E, Chiamulera C, Bunnemann B (2002) Upregulation of $\left[{ }^{3} \mathrm{H}\right]$ methyllycaconitine binding sites following continuous infusion of nicotine, without changes of $\alpha 7$ or $\alpha 6$ subunit mRNA: an autoradiography and in situ hybridization study in rat brain. Eur J Neurosci 16:1633-1646. Medline

Munro G, Hansen R, Erichsen H, Timmermann D, Christensen J, Hansen H (2012) The alpha7 nicotinic ACh receptor agonist compound $\mathrm{B}$ and positive allosteric modulator PNU-120596 both alleviate inflammatory hyperalgesia and cytokine release in the rat. $\mathrm{Br}$ J Pharmacol 167:421-435. CrossRef Medline

Nagakura Y, Okada M, Kohara A, Kiso T, Toya T, Iwai A, Wanibuchi F, Yamaguchi T (2003) Allodynia and hyperalgesia in adjuvantinduced arthritic rats: time course of progression and efficacy of analgesics. J Pharmacol Exp Ther 306:490-497. CrossRef Medline

Navratilova E, Porreca F (2014) Reward and motivation in pain and pain relief. Nat Neurosci 17:1304-1312. CrossRef Medline

Nirogi R, Goura V, Abraham R, Jayarajan P (2013) alpha4beta2* neuronal nicotinic receptor ligands (agonist, partial agonist and positive allosteric modulators) as therapeutic prospects for pain. . Eur J Pharmacol 712:22-29. CrossRef Medline

Ossipov MH, Dussor GO, Porreca F (2010) Central modulation of pain. J Clin Invest 120:3779-3787. CrossRef Medline

Panagis G, Kastellakis A, Spyraki C, Nomikos G (2000) Effects of methyllycaconitine (MLA), an $\alpha_{7}$ nicotinic receptor antagonist, on nicotine- and cocaine-induced potentiation of brain stimulation reward. Psychopharmacology (Berl) 149:388-396. Medline

Patterson AL, Gritzner S, Resnick MP, Dobscha SK, Turk DC, Morasco BJ (2012) Smoking cigarettes as a coping strategy for chronic pain is associated with greater pain intensity and poorer pain-related function. J Pain 13:285-292. CrossRef Medline

Picciotto MR, Caldarone BJ, Brunzell DH, Zachariou V, Stevens TR, King SL (2001) Neuronal nicotinic acetylcholine receptor subunit 
knockout mice: physiological and behavioral phenotypes and possible clinical implications. Pharmacol Ther 92:89-108. Medline

Picciotto MR, Higley MJ, Mineur YS (2012) Acetylcholine as a neuromodulator: cholinergic signaling shapes nervous system function and behavior. Neuron 76:116-129. CrossRef Medline

Ramirez-Latorre J, Yu CR, Qu X, Perin F, Karlin A, Role L (1996) Functional contributions of $\alpha 5$ subunit to neuronal acetylcholine receptor channels. Nature 380:347-351. CrossRef

Ren K, Dubner R (1999) Central nervous system plasticity and persistent pain. J Orofac Pain 13:155-163. Medline

Ren K, Dubner R (2002) Descending modulation in persistent pain: an update. Pain 100:1-6. Medline

Rowbotham MC, Arslanian A, Nothaft W, Duan WR, Best AE, Pritchett Y, Zhou Q, Stacey BR (2012) Efficacy and safety of the alpha4beta2 neuronal nicotinic receptor agonist ABT-894 in patients with diabetic peripheral neuropathic pain. Pain 153:862-868. CrossRef Medline

Rowbotham MC, Duan WR, Thomas J, Nothaft W, Backonja MM (2009) A randomized, double-blind, placebo-controlled trial evaluating the efficacy and safety of ABT-594 in patients with diabetic peripheral neuropathic pain. Pain 146:245-252. CrossRef Medline

Sagen J, Proudfit HK (1985) Evidence for pain modulation by preand postsynaptic noradrenergic receptors in the medulla oblongata. Brain Res 331:285-293. Medline

Samengo IA, Currò D, Martire M (2015) Nicotinic receptors modulate the function of presynaptic AMPA receptors on glutamatergic nerve terminals in the trigeminal caudal nucleus. Neurochem Int 90:166-172. CrossRef Medline

Schepers RJ, Mahoney JL, Shippenberg TS (2008) Inflammationinduced changes in rostral ventromedial medulla mu and kappa opioid receptor mediated antinociception. Pain 136:320-330. CrossRef Medline

Shi Y, Weingarten TN, Mantilla CB, Hooten WM, Warner DO (2010) Smoking and pain: pathophysiology and clinical implications. Anesthesiology 113:977-992. CrossRef Medline

Tribollet E, Bertrand D, Marguerat A, Raggenbass M (2004) Comparative distribution of nicotinic receptor subtypes during development, adulthood and aging: an autoradiographic study in the rat brain. Neuroscience 124:405-420. CrossRef Medline

Tsutsui-Kimura I, Ohmura Y, Izumi T, Yamaguchi T, Yoshida T, Yoshioka M (2010) Nicotine provokes impulsive-like action by stimulating $\alpha 4 \beta 2$ nicotinic acetylcholine receptors in the infralimbic, but not in the prelimbic cortex. Psychopharmacology (Berl) 209:351-359. CrossRef

Ueda $M$, lida $Y$, Tominaga A, Yoneyama $T$, Ogawa $M$, Magata $Y$, Nishimura H, Kuge Y, Saji H (2010) Nicotinic acetylcholine receptors expressed in the ventralposterolateral thalamic nucleus play an important role in anti-allodynic effects. $\mathrm{Br} \mathrm{J}$ Pharmacol 159: 1201-1210. CrossRef Medline

Umana IC, Daniele CA, McGehee DS (2013) Neuronal nicotinic receptors as analgesic targets: it's a winding road. Biochem Pharmacol 86:1208-1214. CrossRef Medline

Vanegas $\mathrm{H}$ (2004) To the descending pain-control system in rats, inflammation-induced primary and secondary hyperalgesia are two different things. Neurosci Lett 361:225-228. CrossRef Medline
Vanegas H, Schaible HG (2004) Descending control of persistent pain: inhibitory or facilitatory? Brain Res Rev 46:295-309. CrossRef Medline

Whiteaker P, Sharples CGV, Wonnacott S (1998) Agonist-induced up-regulation of alpha 4 beta 2 nicotinic acetylcholine receptors in M10 cells: pharmacological and spatial definition. Mol Pharmacol 53:950-962.

Wieskopf JS, Mathur J, Limapichat W, Post MR, Al-Qazzaz M, Sorge RE, Martin LJ, Zaykin DV, Smith SB, Freitas K, Austin JS, Dai F, Zhang J, Marcovitz J, Tuttle AH, Slepian PM, Clarke S, Drenan RM, Janes J, Al Sharari S, Segall SK, Aasvang EK, Lai W, Bittner R, Richards CI, Slade GD, Kehlet H, Walker J, Maskos U, Changeux JP, Devor M, Maixner W, Diatchenko L, Belfer I, Dougherty DA, Su Al, Lummis SC, Imad Damaj M, Lester HA, Patapoutian A, Mogil JS (2015) The nicotinic alpha6 subunit gene determines variability in chronic pain sensitivity via cross-inhibition of $\mathrm{P} 2 \mathrm{X} 2 / 3$ receptors. Sci Translat Med 7:287ra272. CrossRef

Wonnacott S (2014) Nicotinic ACh receptors. Tocris Biosci Sci Rev Ser 1-29.

Wonnacott S, Barik J (2007) Nicotinic ACh receptors. Tocris Rev 28:1-20.

World Health Organization (2011) Assessment of the Economic Costs of Smoking. Geneva, Switzerland, WHO.

Wu J, Lukas RJ (2011) Naturally-expressed nicotinic acetylcholine receptor subtypes. Biochem Pharmacol 82:800-807. CrossRef Medline

Xanthos DN, Beiersdorf JW, Thrun A, lanosi B, Orr-Urtreger A, Huck S, Scholze P (2015) Role of alpha5-containing nicotinic receptors in neuropathic pain and response to nicotine. Neuropharmacology 95:37-49. CrossRef Medline

Yagoubian B, Akkara J, Afzali P, Alfi DM, Olson L, Conell-Price J, Yeh $\mathrm{J}$, Eisig SB, Flood $\mathrm{P}$ (2011) Nicotine nasal spray as an adjuvant analgesic for third molar surgery. J Oral Max Surg 69:1316-1319. CrossRef

Yang KC, Jin GZ, Wu J (2009) Mysterious $\alpha 6$-containing nAChRs: function, pharmacology, and pathophysiology. Acta Pharmacol Sin 30:740-751. CrossRef Medline

Young T, Wittenauer S, Parker R, Vincler M (2008) Peripheral nerve injury alters spinal nicotinic acetylcholine receptor pharmacology. Eur J Pharmacol 590:163-169. CrossRef Medline

Zhang J, Xiao Y-D, Jordan KG, Hammond PS, Van Dyke KM, Mazurov AA, Speake JD, Lippiello PM, James JW, Letchworth SR, Bencherif M, Hauser TA (2012) Analgesic effects mediated by neuronal nicotinic acetylcholine receptor agonists: Correlation with desensitization of $\alpha 4 \beta 2 *$ receptors. Eur J Pharm Sci 47:813-823. CrossRef Medline

Zhu CZ, Chin CL, Rustay NR, Zhong C, Mikusa J, Chandran P, Salyers A, Gomez E, Simler G, Lewis LG, Gauvin D, Baker S, Pai M, Tovcimak A, Brown J, Komater V, Fox GB, Decker MW, Jacobson PB, Gopalakrishnan M, Lee CH, Honore P (2011) Potentiation of analgesic efficacy but not side effects: co-administration of an $\alpha 4 \beta 2$ neuronal nicotinic acetylcholine receptor agonist and its positive allosteric modulator in experimental models of pain in rats. Biochem Pharmacol 82:967-976. CrossRef 